\title{
The Effect of Health Insurance on Retirement
}

FOR DECADES health insurance in the United States has been provided to most nonelderly Americans through their own or a family member's employment. This system of employment-based health insurance has evolved largely because of the substantial cost advantages that employers enjoy in supplying health insurance. By pooling large numbers of individuals, employers face significantly lower administrative expenses than do individuals. In addition, employer expenditures on health insurance are tax deductible, but individual expenditures are generally not. ${ }^{1}$

Despite these cost advantages, there is widespread dissatisfaction with this system of employment-based health insurance. Many people are excluded because not all employers provide health insurance and not all individuals live in households in which someone is employed. An estimated 36 million Americans were uninsured in $1990 .^{2}$ Even among those fortunate enough to have employer-provided health insurance, there is mounting concern that it discourages individuals with preexisting conditions from changing jobs and, for those who do change jobs, it often means finding a new doctor because insurance plans vary from firm to firm.

I wish to thank Gary Burtless, David Cutler, Jon Gruber, Jerry Hausman, Jim Poterba, and Andrew Samwick for their comments and suggestions.

1. Under current tax law, there are two circumstances in which individuals may deduct their expenditures on health insurance: (1) those who are self-employed and who do not have access to employer-provided health insurance through another job or their spouse's employment may deduct 25 percent of their expenditures on health insurance, and (2) those who itemize may deduct their medical expenses, including the cost of health insurance, to the extent that these expenditures exceed 7.5 percent of income.

2. Piacentini and Foley (1992, p. 185). 
This dissatisfaction with the present system of employer-provided health insurance is one of the factors driving the current move toward health care reform. Most proposals specifically address the problems of access and continuity of coverage outlined above. For example, under President Clinton's plan, employers must help pay for the insurance of their employees but need not provide it directly. Employees at firms that opt not to provide insurance would be covered by a plan of the employee's choosing provided through a regional health alliance, which would be able to achieve the same cost savings as employers. Although individuals who are unemployed or who choose not to work would have to pay the full cost of their insurance, government subsidies would be available to help defray the costs for those with low incomes and for early retirees. And all plans, whether provided by an employer or a health alliance, would prohibit insurers from excluding preexisting conditions. While other proposals differ in their approach to reform, most, like the Clinton plan, will fundamentally change the way that health care is either financed or delivered.

Given the current relationship between health insurance and employment, any health care reform will affect the structure of the labor market. This paper explores one piece of the employment relationship that is likely to change: the decision to retire. Just as employer-provided health insurance is thought to deter job mobility, it is also likely to deter retirement.

Various aspects of the proposals raise three important issues regarding the effects of reform on retirement. The first is the extent to which the provision of health insurance is tied to employment. Severing the link between employment and the receipt of health insurance will increase the incentives to retire early among those who fear losing health insurance coverage if they do so. But mandating that all employers provide health insurance may also postpone the retirement of some older workers whose employers did not previously provide health insurance. The second issue is whether the plan establishes purchasing pools that make nonemployment-based health insurance available to individuals at the lower rates usually achieved by firms. These pools would reduce the cost of health insurance in the private market and would therefore encourage early retirement. The third issue is whether the plan subsidizes the purchase of individual health insurance by early retirees. Such subsidies further reduce the cost of purchasing private health insurance and would therefore provide an additional incentive for early retirement. 
To evaluate the effect that different reform proposals might have on retirement, one must know the extent to which health insurance influences the retirement decision. This paper attempts to quantify this effect. I begin by examining whether health insurance affects other types of labor market behavior, such as job mobility and labor force participation. To the extent that health insurance affects these other types of behavior, it is likely to influence retirement. I then examine the factors that make health insurance an important consideration in deciding whether to retire. These include the need for health insurance, which rises with age, and the availability of health insurance after retirement. Among individuals aged 55-64, those who are not employed are much less likely to be covered by employer-provided health insurance and much more likely to be either uninsured or covered by an individual nongroup policy or government-sponsored health insurance. To the extent that the latter types of insurance are inferior to employer-provided health insurance, they may defer retirement.

Given these reasons why health insurance should affect retirement, I then briefly review the existing literature on health insurance and retirement. Previous work in this area is limited, mainly because there are few data sets that describe both health insurance and labor market behavior. My analysis uses three individual-level data sets: the 1987 National Medical Expenditure Survey and two subsets of the Survey of Income and Program Participation. All three include questions on the age at retirement and the availability of employer-provided postretirement health insurance.

The next section of the paper describes the availability and structure of postretirement health insurance benefits. Although the provision of these benefits has increased over time, less than half of the work force is currently employed by firms offering health insurance to retirees. As might be expected, workers in large firms and those employed in highwage industries are more likely to receive such benefits. Surprisingly, eligibility to receive retiree health benefits is tied to the receipt of other retirement benefits, such as a pension, for only one-quarter of workers.

Using the data described above, I then examine the effect of retiree health insurance on age at retirement. I find that those with employerprovided postretirement health insurance retire 5-16 months earlier than those without such insurance. This result is robust using various definitions of retirement and regardless of whether individuals receive a pension. It is less clear, however, whether this is the effect of actually 
having retiree health insurance or whether a firm's provision of retiree health insurance is correlated with overall job quality, the generosity of pension benefits, and any incentives for early retirement that are part of the pension plans in these firms.

Finally, I try to answer three questions about health insurance and retirement. The first is what impact health care reform might have on the labor force participation of older individuals. I estimate that universal coverage would reduce the labor force participation of men aged 60-64 by 4.3 percentage points. To the extent that reform is financed through payroll taxes rather than through individual contributions, such a labor supply response would reduce the revenue that the government collects from these taxes.

Second, I ask to what extent the increased availability of retiree health insurance explains the aggregate trend toward early retirement. The labor force participation of men aged 55-64 has fallen steadily over the past several decades. Much of this decline is attributable to the increased generosity of both social security and private pensions. However, these two factors together can explain only one-third to one-half of the decline in aggregate labor force participation. Over this same time period, the availability of retiree health insurance has increased as well. My estimates suggest that the increased availability of postretirement health insurance can explain between 10 and 20 percent of the overall decline in the labor force participation of older men.

The third question is whether eligibility for Medicare explains the "excess" spike in the probability of retirement (the retirement hazard) at age 65 . The social security system and many private pensions provide incentives to retire at age 65 ; consequently, some spike in the retirement hazard at this age is not surprising. However, the financial incentives associated with social security and pensions do not fully account for the spike at $65 .{ }^{3}$ One potential explanation is that individuals wait until they are eligible for Medicare before they retire in order to avoid being uninsured or having to purchase insurance in the private market. If this is true, the excess spike should exist only for those with retiree health insurance. I find little evidence of this. Although health insurance clearly affects retirement, Medicare does not appear to explain the excess retirement that occurs at age 65 .

3. Lumsdaine, Stock, and Wise (forthcoming). 


\section{Health Insurance and the Labor Market}

A substantial fraction of the expenditures on employee compensation is for benefits rather than for direct wage payments; in 1990, employers spent $\$ 546$ billion on benefits, about 17 percent of total compensation. ${ }^{4}$ It would be surprising, therefore, for benefits not to affect the labor market behavior of individuals and firms. Although much research has examined the role of pensions in the labor market, little work has been done on the role of health insurance, despite the fact that employers spend more on health insurance than on any other employee benefit. In 1990, outlays on health insurance totaled $\$ 174.2$ billion compared with $\$ 127$ billion spent on pension plans and $\$ 137$ billion on mandated employer contributions to social security. Furthermore, health insurance expenditures are the fastest growing component of benefit payments, increasing at an average rate of 15.6 percent annually over the $1948-90$ period. ${ }^{5}$ Employer-provided health insurance also affects more individuals than do private pensions. Roughly two-thirds of full-time workers have health insurance through their employers, but only 50 percent participate in employer-sponsored pension plans. Because many firms extend health insurance coverage to family members as well, the actual number of individuals who profit from this type of benefit is even greater.

\section{Health Insurance and Individual Behavior}

There are many ways in which health insurance might affect labor market behavior. Much media attention has recently focused on the extent to which health insurance inhibits job mobility, the problem of "joblock." Interest in this issue was spurred by a front-page article in the New York Times citing a survey in which 30 percent of respondents claimed that "they or someone in their family had, at some time, decided to stay in a job they wanted to leave mainly because they did not want to lose health coverage." ${ }^{6}$ Notwithstanding the results of this and other surveys, the actual degree of job-lock is difficult to quantify because job-

4. Piacentini and Foley (1992, p. 12).

5. Piacentini and Foley (1992, pp. 8, 19).

6. See Erick Eckholm, "Health Benefits Found to Deter Switches in Jobs," New York Times, September 26, 1991, p. A1. 
lock cannot be measured in the same way as other economic variables affecting mobility, such as union status, wages, or education. There are, however, observable factors that should be correlated with job-lock, such as the value of health insurance. Individuals who place a high value on health insurance should display a greater sensitivity to its availability when changing jobs than individuals who place a low value on this benefit. Moreover, individuals whose employers do not provide health insurance should not be affected by job-lock since they face no loss in coverage by changing jobs. The degree of job-lock is therefore inferred from the different job turnover rates between those with high and low valuations of health insurance for those with and without employer-provided health insurance.

In other work, I use three different proxies for the value of health insurance in order to estimate the importance of job-lock among married men. ${ }^{7}$ The first is whether the individual has an alternative source of health insurance not linked to his employment, such as that provided by a union or through the job of a working spouse. Having this type of coverage mitigates the cost of changing jobs and should serve to increase mobility and decrease job-lock. The second and third proxies are family size and a wife's pregnancy, both of which should be correlated with expected medical expenses, and thus the value of health insurance. Men with a large family or a pregnant wife presumably place a higher value on health insurance and are less likely to change jobs. Using data from the 1987 National Medical Expenditure Survey, I find that all three factors significantly influence the mobility of male workers, and their effects are more pronounced for those with health insurance than for those without. The results suggest that job-lock accounts for a sizable 25 percent reduction in mobility. This not only directly affects the well-being of those who are "job-locked" but may also affect the economy as a whole if better job matches and corresponding increases in productivity are lost.

Two other studies that conduct similar tests support the existence of job-lock.$^{8}$ Additional corroborating evidence is provided by Jonathan Gruber and myself. We find that laws allowing individuals to maintain their coverage after changing jobs increase mobility and reduce job-

7. Madrian (1994).

8. Cooper and Monheit (1993) use the same data, and Buchmueller and Valletta (1994) use data from the Survey of Income and Program Participation. 
lock. ${ }^{9}$ These results are not undisputed, however. Using data from the Survey of Income and Program Participation and the 1980 National Medical Care Utilization and Expenditure Survey, John Penrod finds mixed evidence of job-lock. ${ }^{10}$ The findings of Douglas Holtz-Eakin, using data from the Panel Study of Income Dynamics, suggest little joblock. ${ }^{11}$ This latter study is the only one that fails to find evidence of joblock, and the quality of its data makes it difficult to know whether the paper finds evidence against job-lock or simply against the turnover data in the panel study. ${ }^{12}$ Despite the somewhat contradictory results in these latter two studies, the weight of the evidence supports the conclusion that health insurance is an important factor in the decision to change jobs.

Health insurance is also an important consideration in deciding whether to leave welfare. Individuals on welfare receive insurance coverage through Medicaid and lose the coverage once they cease to be eligible for welfare. Because the types of jobs that most individuals on welfare are likely to get if they choose to work do not offer health insurance, poor individuals may decide against leaving welfare simply to maintain their Medicaid benefits. Three recent studies all find that losing Medicaid is a substantial deterrent to leaving welfare. ${ }^{13}$

There are several other ways that health insurance might affect labor market outcomes. Health insurance might affect the decision to become self-employed,${ }^{14}$ the duration of unemployment, the supply of labor by secondary earners, the number of hours worked, and the choice of a job. Firm behavior may also be influenced by health insurance through the total demand for labor, the relative demand for high- versus low-wage employees, the compensation packages it chooses to offer, the decision to subcontract for various types of labor services, and the decision to be "big" or "small." Although there is little evidence on the empirical significance of most of these effects, the many avenues through which

9. Gruber and Madrian (1994).

10. Penrod (1993).

11. Holtz-Eakin, Penrod, and Rosen (1994).

12. The Panel Study of Income Dynamics has very noisy and inconsistent measures of turnover. Brown and Light (1992) suggest that the results of estimating job turnover equations with these data are particularly sensitive to how the data are cleaned.

13. See Yelowitz (1993), Moffitt and Wolfe (1992), and Ellwood and Adams (1990).

14. Holtz-Eakin, Penrod, and Rosen (1994) have done work suggesting that the effect of health insurance on self-employment is small. 
Figure 1. Employer-Provided Postretirement Health Insurance by Age at Retirement Percent with coverage

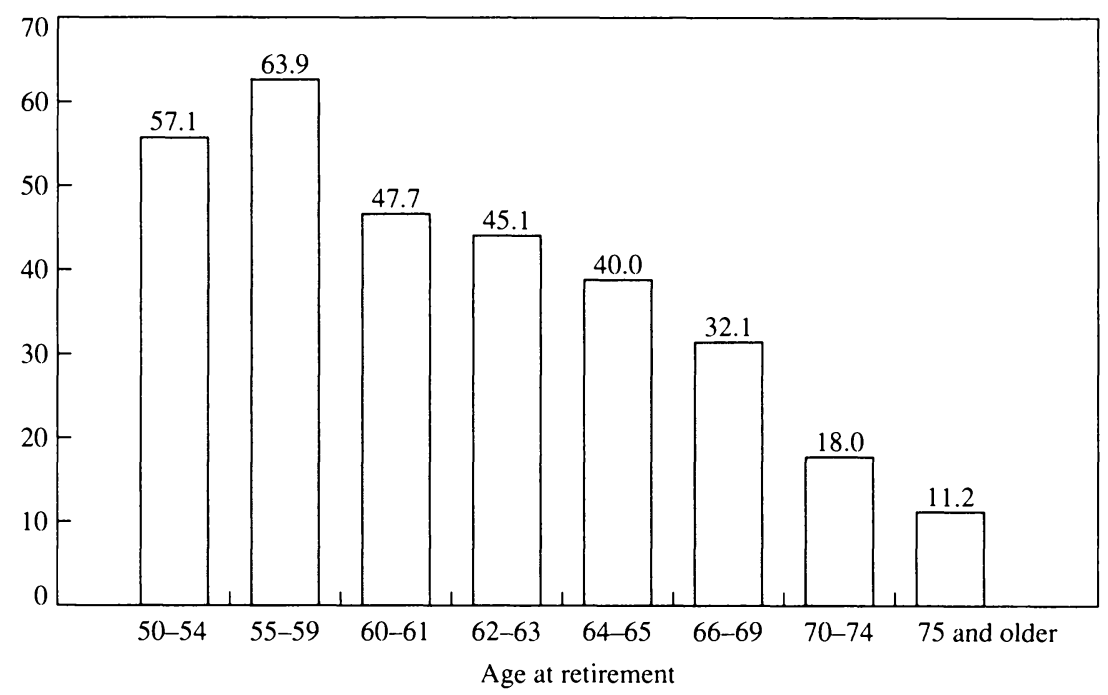

Source: Author's calculations using data from the 1987 National Medical Expenditure Survey.

health insurance can affect both individual and firm behavior reinforce the belief that changes in the health insurance system may significantly affect the labor market.

\section{Health Insurance and Early Retirement}

Given the substantial effect of health insurance on other types of labor market behavior, it is likely that health insurance affects retirement decisions as well. Anecdotal evidence suggests this is the case. A recent Gallup poll reports that 63 percent of working Americans "would delay retirement until becoming eligible for Medicare (age 65) if their employers were not going to provide health coverage" despite the fact that 50 percent "said they would prefer to retire early_by age 62." 15 A simple tabulation of postretirement coverage by age at retirement underscores the importance of health insurance in the decision to retire. As figure 1 shows, workers who retire at younger ages are much more likely to have employer-provided postretirement health insurance than workers who

15. Employee Benefit Research Institute (1990). 
retire at older ages. Almost 64 percent of those who retire between the ages of 55 and 59 have postretirement insurance, but only 32 percent of those retiring between the ages of 66 and 69 have such coverage.

The rationale for why health insurance should affect retirement is straightforward. As noted earlier, the vast majority of individuals in the United States receive their health insurance coverage through their own employment or that of a family member. This insurance is not typically portable, however. That is, when an individual quits his or her job, the insurance coverage associated with that job ceases as well. ${ }^{16}$ Once individuals reach age 65 , health insurance coverage is no longer a problem because everyone 65 years or older, whether retired or not, is eligible for Medicare. But unlike social security, one cannot qualify for Medicare before age 65 . For some individuals, this is not a problem since their employer provides postretirement health insurance benefits for early retirement, but for the majority of workers early retiree benefits are not available through their employer.

Of course, individuals contemplating early retirement can purchase health insurance in the private market, but this may be an unattractive option for older individuals for several reasons. One is that employers can provide insurance at a much lower price than that faced by individuals in the private market. By pooling the risks of many individuals, employers can reduce adverse selection and lower administrative expenses. These two factors alone reduce the cost of providing insurance in large firms by 35 percent. ${ }^{17}$ In addition, health insurance available to individuals tends to be less generous than that provided by employers: it comes with higher copayments and deductibles and is less likely to cover benefits like diagnostic services and prescription drugs. ${ }^{18} \mathrm{~A}$ potentially more important factor than either cost or generosity of benefits, however, is the fact that exclusions of preexisting conditions are typical of almost all individual policies. For individuals with health problems, they make the relative cost of health insurance in the private market even greater. The cost and risk associated with buying health insurance

16. Federal legislation under the Consolidated Omnibus Budget and Reconciliation Act of 1985 (COBRA) now allows individuals to maintain their health insurance through a former employer for up to 18 months; the individual, however, must pay the full cost of the coverage. Gruber and Madrian (1993a, 1993b) examine the effects of this legislation and similar state laws on the age at retirement of older workers.

17. Congressional Research Service (1989, p. 46).

18. See Gruber and Madrian (1994) and Farley (1986). 
Table 1. Aging and Health Status

Percent, except expenditures

\begin{tabular}{|c|c|c|c|c|}
\hline \multirow[b]{2}{*}{ Health measure } & \multicolumn{4}{|c|}{ Age group } \\
\hline & $35-44$ & $45-54$ & $55-64$ & $65-74$ \\
\hline \multicolumn{5}{|l|}{ Self-reported health status } \\
\hline Excellent or good health & 86.6 & 80.2 & 68.8 & 56.8 \\
\hline Fair or poor health & 13.4 & 19.8 & 31.2 & 43.2 \\
\hline \multicolumn{5}{|l|}{ Incidence of health problems $\mathrm{s}^{\mathrm{a}}$} \\
\hline One problem & 31.6 & 51.7 & 72.2 & 81.8 \\
\hline Two or more problems & 9.5 & 22.6 & 42.3 & 57.1 \\
\hline Three or more problems & 2.8 & 10.2 & 21.5 & 34.5 \\
\hline \multicolumn{5}{|l|}{ Medical expenditures } \\
\hline Average total medical expenditures ${ }^{b}$ & $\begin{array}{c}1,652 \\
(4,711)\end{array}$ & $\begin{array}{c}2,650 \\
(8,938)\end{array}$ & $\begin{array}{c}3,666 \\
(11,185)\end{array}$ & $\begin{array}{c}5,893 \\
(15,782)\end{array}$ \\
\hline $\begin{array}{l}\text { Average total medical expenditures } \\
\text { if greater than zero }\end{array}$ & $\begin{array}{c}1,957 \\
(5,070)\end{array}$ & $\begin{array}{l}3,106 \\
(9,605)\end{array}$ & $\begin{array}{c}4,125 \\
(11,784)\end{array}$ & $\begin{array}{c}6,348 \\
(16,292)\end{array}$ \\
\hline $\begin{array}{l}\text { Medical expenditures as a percent of } \\
\text { total family income }\end{array}$ & 4.0 & 6.0 & 9.4 & 22.6 \\
\hline
\end{tabular}

Source: Author's calculations using data from the 1987 National Medical Expenditure Survey.

a. The 11 diagnosed health conditions are stroke, cancer, heart attack, gallbladder disease, high blood pressure, arteriosclerosis, rheumatism, emphysema, arthritis, diabetes, and heart disease.

b. Expenditures in dollars are inflated to 1991 prices by the growth in total health care expenditures between 1987 and 1991. Standard deviations of expenditures are given in parentheses.

in the private market may therefore serve as a substantial deterrent to early retirement. Although health insurance is unlikely to affect the decisions of those who want to retire after age 65 , it will be a real concern for the many individuals who would like to retire before age 65 but who do not want to give up their employer-provided health insurance.

The need for health insurance increases with age, as evidenced by the variety of measures shown in table 1 . The first measure, health status, gives the fraction of people in each age group reporting their health to be excellent or good versus fair or poor. Among those aged 55-64, almost one-third reported being in fair or poor health, a substantially higher fraction than among the younger age groups. Although self-reported health status does not necessarily indicate the actual severity of an individual's clinical diagnoses, ${ }^{19}$ it is likely to be an accurate reflection of how much an individual values health insurance.

The need for insurance as measured by actual health conditions also increases with age. Table 1 shows the percent of individuals who report

19. Bazzoli (1985). 
Table 2. Type of Insurance by Age and Employment Status

Percent

\begin{tabular}{|c|c|c|c|c|c|c|}
\hline \multirow[b]{2}{*}{ Insurance } & \multicolumn{3}{|c|}{ Ages 25-54 } & \multicolumn{3}{|c|}{ Ages 55-64 } \\
\hline & All & Employed & $\begin{array}{c}\text { Not } \\
\text { employed }\end{array}$ & All & Employed & $\begin{array}{c}\text { Not } \\
\text { employed }\end{array}$ \\
\hline Employer provided & 71.6 & 78.5 & 44.2 & 64.5 & 76.3 & 51.6 \\
\hline Policy in own name & 51.1 & 62.7 & 4.2 & 44.8 & 63.1 & 24.7 \\
\hline Other group coverage & 1.2 & 1.1 & 1.3 & 4.1 & 4.0 & 4.3 \\
\hline Nongroup insurance & 5.9 & 5.8 & 6.2 & 14.5 & 12.6 & 16.6 \\
\hline CHAMPUS-CHAMPVA ${ }^{a}$ & 5.7 & 4.9 & 8.8 & 7.7 & 6.4 & 9.2 \\
\hline Medicare or Medicaid & 5.6 & 1.2 & 23.4 & 10.4 & 0.8 & 20.9 \\
\hline Uninsured & 15.4 & 13.5 & 23.0 & 12.0 & 10.1 & 14.1 \\
\hline
\end{tabular}

Source: Author's calculations using data from the 1987 National Medical Expenditure Survey.

a. CHAMPUS and CHAMPVA stand for Civilian Health and Medical Program for the Uniformed Services and Civilian Health and Medical Program for the Veterans Administration, respectively.

having been diagnosed with 1 or more of 11 health conditions ranging from cancer, to a heart attack, to high blood pressure, to arthritis. As can be seen, the likelihood of having one of these conditions increases dramatically between the ages of 45-54 and 55-64. Almost three-quarters of those aged 55-64 have been diagnosed with at least 1 of the 11 conditions, and mure than 20 percent have been diagnosed with 3 or more.

A third measure of the need for health insurance, also shown in table 1, is actual expenditures on health care. Average total expenditures of those aged 55-64 were $\$ 3,666$ in 1991 dollars. That is almost 40 percent greater than the average total expenditures of those aged 45-54 and more than twice that of individuals aged 35-44. Average expenditures conditional on having had any expenditures show a similar pattern. Not only do expenditures increase with age, but their variance increases as well. The last row of table 1 gives individual medical expenditures as a percent of total family income. Medical expenses, which constitute only 4 percent of income for those aged 35-44, climb to almost 10 percent of income for those aged 55-64. As these percentages reflect only individual expenditures, total family expenditures would constitute an even larger portion of income.

Given this supposed need for health insurance, what type of coverage do older individuals have? Table 2 illustrates the sources of health insurance coverage by age and employment status. The first row shows the importance of employer-provided health insurance at all ages, regard- 
less of whether an individual works. There are, nevertheless, significant differences in coverage arising from employment status. Among those aged 55-64, persons who are not employed are much less likely to have employer-provided health insurance, particularly in their own name, and more likely than their employed counterparts to be covered by a nongroup policy or to be uninsured. This implies that early retirement is often accompanied by changes in the type of private insurance coverage available to individuals.

\section{Evidence on Health Insurance and Retirement}

Despite a vast literature on the effects of social security, pensions, health status, and disability insurance on retirement, only a few very recent papers examine the relationship between health insurance and retirement. It should be said at the outset that the biggest obstacle to overcome in this research is finding appropriate data with which to estimate such a relationship. Robin Lumsdaine, James Stock, and David Wise use detailed data on employees from a single firm to discern whether eligibility for Medicare can explain the "excess" retirement observed at age $65 .{ }^{20}$ Their results suggest that Medicare has little effect on retirement, but it is difficult to apply this finding to the population at large because the individuals in their sample all worked for the same firm, and that firm happened to provide retiree health insurance. With employerprovided postretirement health insurance available, it is not surprising that Medicare would not affect the retirement decision of this sample of individuals.

Lynn Karoly and Jeannette Rogowski attempt to exploit cross-firm variation in the availability of retiree health insurance. ${ }^{21}$ They use the 1984 Survey of Income and Program Participation to estimate the probability that individuals retire over the course of an approximately twoyear period based on whether they are likely to have retiree health insurance. Because they lack actual data on retiree health insurance, they impute its provision based on firm size and industry. Although they find that their imputed measure of retiree health insurance increases the retirement hazard by 50 percent, it is probably an overestimate, since firm

20. Lumsdaine, Stock, and Wise (forthcoming).

21. Karoly and Rogowski (1993). 
size and industry almost certainly help determine retirement themselves, especially to the extent that they are correlated with the provision of pensions.

Gruber and Madrian circumvent the problem of having to impute retiree health insurance by evaluating the effect on retirement of an exogenous source of health insurance-that provided through state and federal "continuation of coverage" mandates (also known as COBRA provisions). ${ }^{22}$ These mandates allow individuals to continue purchasing health insurance through a previous employer for a specified number of months after leaving the firm. Their results suggest that one year of continuation coverage increases retirement rates by 20 percent. The strength of the Gruber and Madrian analysis is that this type of health insurance is unlikely to be correlated with other factors affecting retirement. However, it is difficult to generalize to other types of health insurance because continuation coverage is limited to 18 months.

Finally, Alan Gustman and Thomas Steinmeier use the Retirement History Survey to estimate a structural model of retirement that incorporates the value of retiree health insurance, in addition to information on pension accruals. ${ }^{23}$ Their model requires defining the point in time at which individuals become eligible for retiree health insurance. They assume that this coincides with pension eligibility; as will be shown later, however, this is true only for one-quarter of those with retiree health insurance. Their paper suggests that health insurance has only a relatively small effect on retirement, but this result is difficult to interpret given the forced collinearity of pension benefits and health insurance in the data.

The present paper exploits three as yet unutilized data sets-the 1987 National Medical Expenditure Survey (NMES) and two supplements to the Survey of Income and Program Participation (SIPP)— to estimate the effect of health insurance on retirement. All three data sets include information about the availability of employer-provided retiree health insurance and age at retirement. Although these data and the ensuing analysis have their limitations, they also have certain advantages relative to the previous research on retirement and health insurance. First, I am able to use actual data on employer-provided postretirement health insurance rather than having to impute such coverage, as Karoly and

22. See Gruber and Madrian (1993a, 1993b).

23. Gustman and Steinmeier (1993). 
Rogowski do. Second, because this paper focuses on the effects of retiree health insurance in a representative sample of individuals, it should be easier to generalize its results than those in Lumsdaine, Stock, and Wise or in Gruber and Madrian. Third, the estimation of a reduced-form rather than a structural model does not require assumptions about either the individual valuation of retiree health insurance or its accrual.

\section{Structure of Postretirement Health Insurance Benefits}

Because the primary variable of interest in the ensuing analysis is retiree health insurance, this section of the paper provides some background on the availability and structure of postretirement health insurance benefits. Before Medicare, private health insurance for the elderly was not widely available. To meet the health care needs of their retired employees, firms began providing postretirement health insurance benefits in the late 1940s and 1950s. At that time the labor force was growing; there were relatively few retirees; and real medical costs were substantially lower than they are today. Therefore, the costs of providing these benefits were largely inconsequential. When Medicare assumed the major portion of health care expenditures for the elderly in 1965, providing such benefits became even more attractive to firms, and many began to furnish supplemental health care benefits for their retirees to cover deductibles and other costs not paid by Medicare.

Although there are no consistent time series data to show the rise in the availability of postretirement health insurance, this growth can be seen in figures 2 and 3, which look in a cross-section at coverage rates by age and year of retirement. Figure 2 shows that the young retired (those aged 65-74) are much more likely to have postretirement health benefits than the old retired (those over age 80 ). This suggests that the availability of such benefits grew from a little more than 20 percent in the 1960s, when the old retired left their jobs, to nearly 45 percent in the late 1970s and early 1980s, when the young retired left their jobs. Figure 3, which shows coverage rates by year of retirement, reveals a similar pattern. Nearly 30 percent of those retiring in the early 1960 s received postretirement health insurance, while more than 45 percent of those retiring during the late 1970s and 1980s received such coverage.

Information on the availability of postretirement health insurance among the currently employed supports these figures. Data from the 
Figure 2. Employer-Provided Postretirement Health Insurance by Age

Percent with coverage

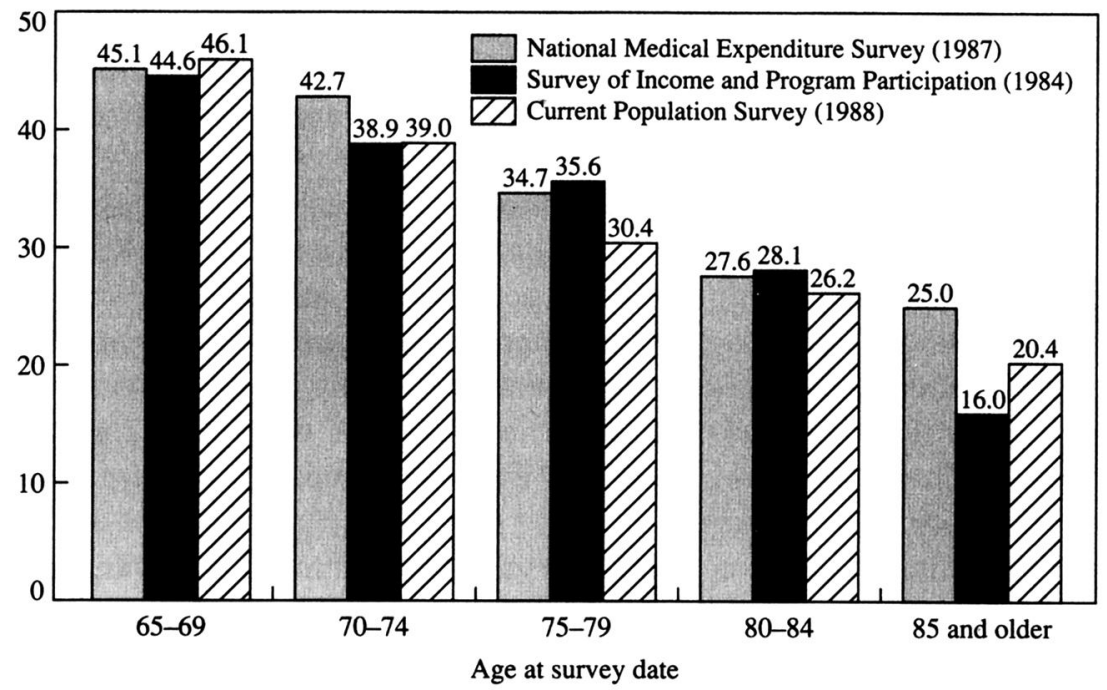

Source: Author's calculations using data from the 1987 National Medical Expenditure Survey, the 1984 Survey of Income and Program Participation, and Current Population Survey, August 1988.

Figure 3. Employer-Provided Postretirement Health Insurance by Year of Retirement

Percent with coverage

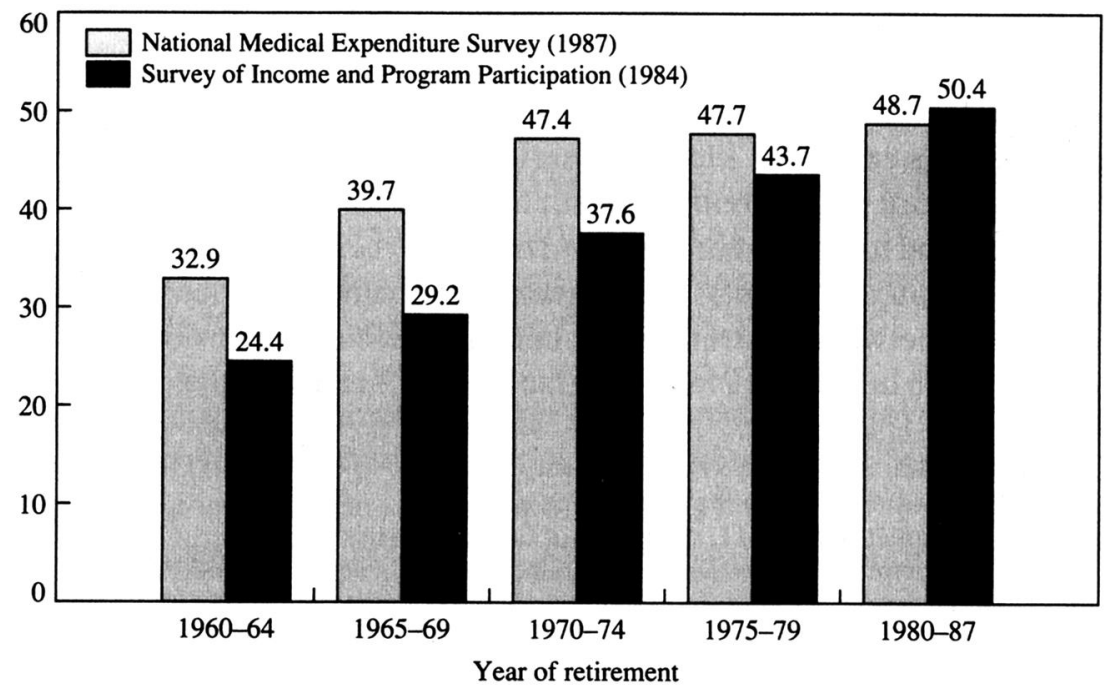

Source: Author's calculations using data from the NMES and the SIPP. 
August 1988 supplement to the Current Population Survey on retiree health insurance suggest that 48.7 percent of employees over age 40 had health insurance benefits that continued beyond retirement. ${ }^{24}$ Firmlevel data paint a similar picture: in 1988, 45 percent of full-time employees in medium-sized and large firms under age 65 were eligible for retiree health benefits upon retirement. ${ }^{25}$

The types of firms that provide postretirement health insurance benefits vary, as do the types of individuals who receive them. As might be expected given the relationship between firm size and the provision of other employee benefits, large firms are much more likely to provide postretirement health benefits than small firms. Only 15 percent of firms with fewer than 100 workers provide such benefits, while more than 80 percent of firms with more than 2,500 employees supply postretirement health insurance benefits. ${ }^{26}$

Table 3 illustrates the considerable variation within industries and occupations in the receipt of postretirement health insurance. For the industry data, more than two-thirds of the individuals who retire from jobs in public administration receive postretirement health insurance, but less than 15 percent of those in sales, personal services, and agriculture do so. Industries that are more likely to provide pensions and health insurance to their active employees are more likely to provide postretirement health insurance as well.

One surprising feature of many postretirement health insurance benefit plans, several of which are shown in table 4 , is that eligibility is not necessarily tied to the receipt of other retirement benefits, such as a pension, or to an employee's length of service..$^{27}$ For only about one-quarter of workers are postretirement health benefits contingent on pension recipiency; and for more than one-third of employees, no prerequisites exist (other than retirement) for the receipt of benefits. Another significant difference between postretirement health benefits and pension benefits is that health benefits are rarely portable. That is, an employee's entitle-

24. Piacentini and Foley (1992, p. 229, table 6.28).

25. U.S. Bureau of Labor Statistics (1989, table 60).

26. See Chollet (1989) and U.S. Bureau of Labor Statistics (1991).

27. The receipt of pensions and postretirement health benefits are nevertheless highly correlated. Data from the 1984 Survey of Income and Program Participation suggest that among men aged 65 and older who are not in the labor force, 88 percent of those with postretirement health insurance also receive pension benefits (author's calculation using the SIPP-EWH data described later in the text). 
Table 3. Individuals with Health Insurance and Pension Benefits by Industry and Occupation

Percent

\begin{tabular}{lccc}
\hline \multicolumn{1}{c}{$\begin{array}{c}\text { Retiree } \\
\text { Industry or }\end{array}$} & $\begin{array}{c}\text { health } \\
\text { insurance } \\
(\text { NMES })\end{array}$ & $\begin{array}{c}\text { Health } \\
\text { insurance } \\
\text { (CPS) }\end{array}$ & $\begin{array}{c}\text { Pension } \\
\text { (CPS) }\end{array}$ \\
\hline Industry & & & \\
Agriculture, forestry, and fishing & 5.7 & 27.4 & 10.1 \\
Construction & 31.0 & 49.9 & 28.6 \\
Manufacturing & 46.8 & 80.8 & 59.6 \\
Transportation, utilities, and communication & 56.5 & 78.7 & 64.3 \\
Sales & 13.8 & 55.1 & 31.0 \\
Finance, real estate, and insurance & 32.7 & 69.3 & 50.4 \\
Personal services & 7.4 & 51.4 & 26.3 \\
Professional services & 35.2 & 64.5 & 54.3 \\
Public administration & 66.7 & 81.8 & 84.0 \\
Occupation & & & \\
Professional and technical & 50.1 & 73.6 & 61.1 \\
Clerical & 42.6 & 66.1 & 52.2 \\
Sales & 16.7 & 58.0 & 33.6 \\
Managerial and administrative & 38.9 & 74.2 & 53.9 \\
Craftsmen and foremen & 45.9 & 67.5 & 46.9 \\
Operatives & 35.3 & 72.1 & 49.5 \\
Transportation operatives & 41.7 & 66.7 & 46.8 \\
Service workers & 21.5 & 37.8 & 23.8 \\
Nonfarm laborers & 37.4 & 59.9 & 54.2 \\
\hline
\end{tabular}

Source: Author's calculations based on the 1987 National Medical Expenditure Survey for individuals aged 55 and older who report having ever retired (weighted) and on the Current Population Survey, March 1988, for working individuals aged $25-50$.

ment to postretirement health insurance does not become vested and is forfeited upon preretirement departure from a firm.

The coverage of postretirement health insurance plans is typically identical to that provided to active employees, with nearly 90 percent of the firms that provide postretirement health coverage also providing the same coverage to retirees under age 65 as to current employees. ${ }^{28}$ Differences in coverage, where they exist, are usually minor, such as reduced coverage for vision care, prescription drugs, and other "noncore" medical benefits. Some companies also require retiree contributions to health insurance premiums, although their plans for active employees are noncontributory. In general, however, these contributions are "rea-

28. Piacentini and Foley (1992, p. 284). 
Table 4. Postretirement Health Insurance: Eligibility and Benefits

Percent of individuals

\begin{tabular}{lcc}
\hline $\begin{array}{c}\text { Health insurance } \\
\text { characteristic }\end{array}$ & $\begin{array}{c}\text { Medium and } \\
\text { large firms, 1989 }\end{array}$ & $\begin{array}{c}\text { State and local } \\
\text { government, 1990 }\end{array}$ \\
\hline $\begin{array}{l}\text { Eligibility } \\
\text { All retirees eligible }\end{array}$ & 39 & 32 \\
Subject to service requirement & 29 & 39 \\
Must qualify for pension & 26 & 20 \\
Benefit level & & \\
No change in coverage & 84 & 87 \\
Reduced coverage & 16 & 13 \\
\hline
\end{tabular}

Source: U.S. Bureau of Labor Statistics $(1989,1991)$.

sonable"; in 1990 , the median contribution for family coverage was $\$ 55$ for pre-65 retirees and $\$ 31$ for post- 65 retirees. ${ }^{29}$

Employer-provided health insurance that is provided for retirees over age 65 must then be coordinated with that provided by Medicare. ${ }^{30}$ The least generous plans simply cover the retiree's Medicare Part B premium or provide supplemental "Medi-Gap" type coverage, which pays for deductibles, copayments, and items such as prescription drugs not covered by Medicare. But most firms continue to include their retirees over age 65 in their regular health plan for active employees and retirees under age $65 .{ }^{31}$

The cost to employers of providing postretirement health insurance depends on several factors including the method used to coordinate benefits and the generosity of the company's health plan. Because Medicare pays some of the costs for individuals over age 65 that would otherwise be paid by firms, the most significant determinant of a firm's total expenditures on retirement health insurance is the number of retirees under age 65. Expenditures on retirees under age 65 are typically double those on retirees over age 65 ; in 1989 , the median cost to firms of providing retiree health insurance to an individual under age 65 was $\$ 2,246$ while that for an individual over age 65 was $\$ 1,033 .^{32}$

29. Hewitt Associates (1990, p. 15).

30. See de Lissovoy and others (1990) for a good explanation of the various ways in which firms coordinate benefits with the coverage provided by Medicare.

31. A. Foster Higgins \& Co., Inc. (1990).

32. Hewitt Associates (1990, p. 12). 


\section{Estimating the Effect of Health Insurance on Retirement}

This section of the paper turns to an estimation of the relationship between retiree health insurance and retirement. By reducing the variance in postretirement consumption associated with uncertainty about medical expenditures, employer-provided retiree health insurance increases the attractiveness of early retirement. Those with retiree health insurance should be more likely to retire in a given year than those without such coverage. Although this effect should be weaker after age 65 , when all individuals become eligible for Medicare, it will not entirely disappear unless Medicare is a perfect substitute for employer-provided health insurance. ${ }^{33}$

\section{Estimation Strategy}

To test for these effects, one would ideally follow a group of not yet retired individuals over time to see whether those with retiree health insurance were more likely to retire than those without such insurance. Unfortunately, there are no longitudinal data currently available with information about whether the health insurance coverage of working individuals will continue after retirement. ${ }^{34}$ There are several sources of data, however, that allow one to identify whether the health insurance coverage of those currently retired comes from a former employer. Thus, I look at the retirement decision retrospectively and consider the effect of postretirement health insurance on the age at retirement among those already retired. The actual equation estimated is of the form

$$
y_{i}=\beta^{\prime} \mathbf{x}_{i}+\gamma R H I_{i}+\epsilon_{i}, \quad \epsilon_{i} \sim N\left(0, \sigma^{2}\right),
$$

where $y_{i}$ is age at retirement, $\mathbf{x}_{i}$ is a vector of demographic characteristics, and $R H I_{i}$ is a dummy variable equal to one if the individual has retiree health insurance.

33. This is unlikely to be true since Medicare coverage is less generous than most employer-provided policies. On average, Medicare covers only about half of the medical expenses of the elderly.

34. The new Health and Retirement Survey conducted by the Survey Research Center at the University of Michigan is collecting this type of information. The first wave of data is scheduled to be released later this year. To conduct a longitudinal analysis of the retirement decision, however, one would have to wait until late 1995 when the second wave of the data becomes available. 
This estimation strategy has one obvious problem: one does not observe the age at retirement for those who are not yet retired. As is typical with this type of censoring, the forced exclusion of these individuals from the regression will tend to bias the estimated coefficients. With the upper tail of the retirement age distribution truncated, the average retirement age in the remaining sample will be too low. In a univariate setting (where postretirement health insurance is the only variable that explains retirement) and with only one cohort of individuals, this truncation will lead to an understatement of the effect of retiree health insurance if such insurance actually does raise the retirement hazard at all ages. This is because at every age, a higher fraction of those without retiree health insurance will be excluded relative to those with retiree health insurance, leading to a greater downward bias in the average retirement age for those without retiree health insurance. In a multivariate setting, however, and with many cohorts each truncated at different ages, the direction of the bias is not unambiguous.

At younger ages, this type of truncation is substantial. In the Current Population Survey, only 24 percent of those aged 55-59 report having ever retired; the remaining 76 percent are still working and would therefore have to be excluded from any estimation of the average age at retirement. Because the magnitude of the bias decreases with the age at which the truncation takes place, one way to reduce the bias is to restrict the sample to cohorts for which a substantial fraction of individuals has already retired. For example, one could look only at individuals over age 70 , an age at which 85 percent of individuals report being out of the labor force. Alternatively, one can account for the truncation directly in the estimation with standard econometric techniques. ${ }^{35}$ (This procedure, called a truncated regression, is outlined in the appendix.)

A second potential problem, for both ordinary least squares estimation and the truncated regression model, is that of mortality. Only those who are alive when the data are collected are included in the sample, and with an older sample mortality is considerable. Of those individuals who are 55 years old today, 83 percent are expected to reach age $65 ; 54$ percent are expected to reach age 75 ; and only 21 percent are expected to reach age $85 .{ }^{36}$ Mortality alone will not necessarily lead to biased coeffi-

35. See Hausman and Wise (1977) and Maddala (1983).

36. See Faber (1982). It is interesting to note that the mortality bias is less severe at younger ages, but this is where truncation is most likely to be a problem. Conversely, at 
cients, however. For example, if the mortality that occurs is completely random, this will make the data more sparse everywhere but should not bias the estimated coefficients.

Of course, mortality might not be random. In particular, those in poor health are likely to die before those who are healthy, and there is much research to suggest that individuals in poor health tend to retire early. ${ }^{37}$ If mortality is only related to $\epsilon$ and not to retiree health insurance, this will bias the estimate of the constant but will not affect the estimated slope parameters. The potential problem arises when premature mortality is more likely among those who retire early and who do not have retiree health insurance. This type of differential mortality could be possible if retiree health insurance improves access to health care and consequently reduces the risk of early death. In this case, the estimated effect of retiree health insurance on age at retirement will be too large..$^{38}$

A growing body of evidence suggests that income and mortality are negatively correlated. ${ }^{39}$ Insofar as retiree health insurance and income are positively correlated, this bias may be present. Explicitly accounting for this bias, however, would entail estimating the relationship between retiree health insurance and mortality, something that is beyond the scope of this paper. The extent of this bias may be moderated by the fact that most mortality occurs after age 65 , and all individuals by this time have access to Medicare.

A third bias could arise if individuals select jobs precisely because they provide health insurance for early retirement. There are two factors, however, that mitigate the potential severity of this bias. The first is that a large fraction of individuals simply do not know whether their job provides retiree health insurance until they get close to retirement. The August 1988 Current Population Survey asked individuals over age 40 with employer-provided health insurance whether their health insur-

older ages, where the selection resulting from mortality is substantial, there is much less truncation.

37. See, for example, Bazzoli (1985), Sammartino (1987), and Burtless (1987).

38. If this bias is present, the growth over time in the availability of retiree health insurance shown in figures 2 and 3 will be understated.

39. Most of the evidence on this front is found in the demography and public health literature. See Smith and Egger (1992) and Wilkinson (1992) for commentaries on this literature and for references to other papers on the topic of demographic characteristics and differential mortality. In the economics literature, this issue has been addressed by Jianakoplos, Menchick, and Irvine (1989) and McClellan and Skinner (1992). 
Figure 4. Tenure at Retirement

Percent of individuals

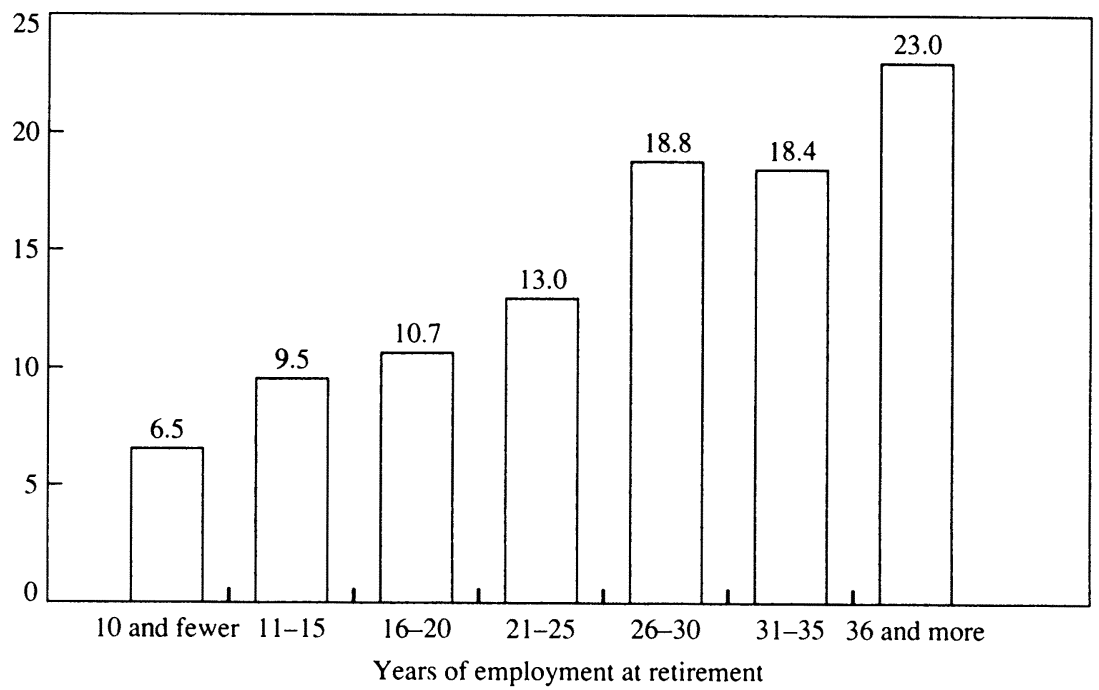

Source: Author's calculations using data from the Survey of Income and Program Participation for men who participated in the Characteristics of the Job from Which Retired module (SIPP-CIR).

ance would continue should they retire. One-third of those aged 40-44 did not know and, even more striking, one-quarter of those aged 60-64 did not know. (Of course, to the extent that individuals are unaware that their employer provides retiree health benefits, the impact of such benefits on the retirement decision will be reduced.) The second factor is that, as shown in figure 4, individuals typically held the job from which they eventually retired for decades. ${ }^{40}$ While possible, it is unlikely that individuals are selecting jobs on the basis of retiree health insurance, a benefit they are not likely to receive for 20 or 30 years and which, in contrast to pension benefits, the firm has no legal requirement to provide.

\section{Data}

To estimate the effect of health insurance on retirement, I use three different data sources. The first, the 1987 NMES, collected detailed information about health status, health insurance, and medical care utili-

40. Author's calculation using data from the SIPP-CJR sample described below. 
zation from approximately 14,000 households. It also collected some information about current and past labor force participation and, in particular, asked all individuals over age 55 whether they had retired from a job or business. The disadvantage of the NMES is that there is no information on either pension or social security recipiency.

The second two sources of data are supplements to the SIPP, a nationally representative survey of households designed to collect information on the economic and demographic characteristics of individuals and their families. Survey participants are interviewed every four months for roughly two-and-one-half years and asked a set of "core" questions pertaining to their labor market activity, income, and participation in welfare and transfer programs over the previous four months. These quarterly interviews are referred to as "waves." In addition, supplemental questions, which change from wave to wave, are asked in socalled topical modules. I use information from two different topical modules.

Wave 3 of the 1984 SIPP panel included a topical module on Education and Work History; I refer to this as the SIPP-EWH data set. As part of this topical module, individuals who did not work during the fourmonth reference period were asked in what year they last worked, the industry of their former employer and their occupation while working, and the reason (including retirement) for leaving their former job. Additional information on retirement is found in the topical module on Characteristics of Job from Which Retired, which was incorporated into the 1984,1985 , and 1986 panels of the SIPP; ${ }^{41}$ this is referred to as the SIPPCJR data set. In this topical module, questions concerning retirement were asked only of those receiving retirement income other than social security. Much more information on the former job is available, however. In addition to the year the last worked, the industry of their former employer, and their occupation while working, this topical module includes questions on firm size, usual hours worked, earnings before retirement, and on whether pension benefits were based on contributions or years of service and pay and whether an individual is now covered by a health plan provided by a former employer.

Because the samples of individuals covered by these two topical modules differ, I treat the SIPP-EWH and the SIPP-CJR data sets sepa-

41. Specifically, I refer to 1984 wave 4, 1985 wave 7 , and 1986 wave 4 . 
rately. ${ }^{42}$ The SIPP-CJR sample is larger because it pools individuals from three different panels. It is confined, however, to those who have received pension income. The SIPP-EWH sample, in contrast, includes everyone who did not work in the previous four months and is therefore more representative. For both samples, I know from the core questionnaire whether an individual is covered by health insurance through a former employer and the amount of pension and social security income an individual is receiving. The supplementary questions in the topical modules provide information on when individuals retired.

In all three data sets, the samples consist of men aged 55-84. I confine the analysis to men largely because the retirement decision for men seems more well defined, especially since I am looking at retirement retrospectively, including time periods in which the labor force participation of women was at a much lower level than it is today. This is also consistent with most of the previous literature on retirement, which has tended to focus exclusively on men (although there is an emerging literature on the retirement of women and the joint retirement decisions of husbands and wives). The lower-age cutoff is dictated by the NMES, which asks retirement questions only of those over age 55 (in general, very few individuals retire before age 55). The upper-age cutoff is dictated by the SIPP, which topcodes its age variable at 85 . The appendix contains descriptive statistics for individuals from all three samples.

As in any study of the retirement decision, the first question to be addressed is how to define retirement. In the previous literature, which has looked mostly at retirement in a dynamic framework, all of the following definitions have been used: (1) a "permanent" departure from the labor force; (2) a substantial reduction in the usual number of hours worked; (3) self-reported retirement; and (4) receipt of pension or social security benefits. The definition chosen is often guided by the data at hand. Unfortunately, it is not possible to get a definition of retirement that is completely consistent across all three data sets, which means that the results from the different data sets are not strictly comparable. The various definitions of retirement do, however, create a way to check the robustness of the results.

Because the estimation results are not particularly sensitive to the

42. Note that those individuals in the 1984 panel who were not working in wave 3 and who received some pension income in wave 4 will be in both the SIPP-EWH and the SIPPCJR samples. 
definition of retirement that is chosen, I focus on one definition of retirement for each data set. In the NMES, retirement is defined as having ever retired and not currently working. In the SIPP-EWH sample, retirement is defined as not working and being out of the labor force. And in the SIPP-CJR sample, retirement is defined as receipt of pension income and not working. (The appendix compares the results for each data set using various different definitions of retirement.)

In this paper, the variable of interest in explaining the retirement decision is whether an individual has retiree health insurance. In the NMES, this is defined by a question specifically about retiree health insurance. In both of the SIPP samples, receipt of retiree health insurance is inferred from questions about whether an individual is covered by any private health insurance, whether this policy is held in the individual's own name, and whether it comes from a current or former employer. For older individuals who are not working, it is likely that any employer-provided coverage held in the individual's own name is from a retiree health insurance policy..$^{43}$ The appendix discusses the precise definition of retiree health insurance in greater detail and compares these two definitions of having retiree health insurance.

The other explanatory variables used in the regressions include race, education, industry, and occupation (although industry and occupation are not available for the 1984 panel in the SIPP-CJR sample). I also use some of the pension information in the SIPP-CJR data. All regressions include a full set of age dummies to account for any cohort effects that might be present. Without these age dummies, the coefficient on retiree health insurance could be picking up a spurious correlation between a secular trend toward earlier retirement and the increased availability of retiree health insurance over the same time period.

\section{Empirical Results}

Table 5 shows the results from a regression of age at retirement on the regressors outlined above using data from the NMES. The first column, which presents the results from an ordinary least squares regression, is

43. For some retirees, this coverage could be COBRA coverage (or continuation coverage under a state law in effect before COBRA). Individuals cease to be eligible for COBRA, however, once they are entitled to Medicare. So for older retirees, this definition should be fairly accurate. 
Table 5. Postretirement Health Insurance and the Age at Retirement (NMES) ${ }^{\text {a }}$

\begin{tabular}{|c|c|c|c|}
\hline \multirow[b]{2}{*}{$\begin{array}{c}\text { Age group, } \\
\text { independent variable, } \\
\text { and summary statistic }\end{array}$} & \multirow{2}{*}{$\begin{array}{c}\text { Ordinary } \\
\text { least squares } \\
\text { No industry and } \\
\text { occupation } \\
\text { dummies }\end{array}$} & \multicolumn{2}{|c|}{ Truncated regression } \\
\hline & & $\begin{array}{l}\text { No industry and } \\
\text { occupation } \\
\text { dummies }\end{array}$ & $\begin{array}{l}\text { Industry and } \\
\text { occupation } \\
\text { dummies }\end{array}$ \\
\hline \multicolumn{4}{|l|}{ Ages $55-84^{\mathrm{b}}$} \\
\hline Constant & $\begin{array}{l}56.230 \\
(0.947)\end{array}$ & $\begin{array}{l}61.456 \\
(2.032)\end{array}$ & $\begin{array}{l}61.040 \\
(2.064)\end{array}$ \\
\hline Retiree health insurance & $\begin{array}{r}-1.187 \\
(0.185)\end{array}$ & $\begin{array}{r}-1.400 \\
(0.217)\end{array}$ & $\begin{array}{c}-1.215 \\
(0.224)\end{array}$ \\
\hline Education & $\begin{array}{c}0.098 \\
(0.028)\end{array}$ & $\begin{array}{c}0.113 \\
(0.033)\end{array}$ & $\begin{array}{c}0.116 \\
(0.038)\end{array}$ \\
\hline Black & $\begin{array}{c}0.194 \\
(0.307)\end{array}$ & $\begin{array}{c}0.237 \\
(0.368)\end{array}$ & $\begin{array}{c}0.208 \\
(0.370)\end{array}$ \\
\hline $\begin{array}{l}\mathrm{R}^{2} \\
\text { Log likelihood }\end{array}$ & $\begin{array}{r}0.253 \\
-4,091.9\end{array}$ & $\begin{array}{r}\cdots \\
-4,007.4\end{array}$ & $\begin{array}{r}\cdots \\
-4,000.4\end{array}$ \\
\hline \multicolumn{4}{|l|}{ Ages $65-84^{\mathrm{b}}$} \\
\hline Constant & $\begin{array}{l}61.375 \\
(0.932)\end{array}$ & $\begin{array}{l}63.065 \\
(1.324)\end{array}$ & $\begin{array}{l}62.838 \\
(1.399)\end{array}$ \\
\hline Retiree health insurance & $\begin{array}{r}-1.320 \\
(0.202)\end{array}$ & $\begin{array}{c}-1.481 \\
(0.225)\end{array}$ & $\begin{array}{r}-1.286 \\
(0.232)\end{array}$ \\
\hline Education & $\begin{array}{c}0.102 \\
(0.031)\end{array}$ & $\begin{array}{c}0.113 \\
(0.034)\end{array}$ & $\begin{array}{c}0.119 \\
(0.039)\end{array}$ \\
\hline Black & $\begin{array}{c}0.267 \\
(0.347)\end{array}$ & $\begin{array}{c}0.302 \\
(0.390)\end{array}$ & $\begin{array}{c}0.309 \\
(0.392)\end{array}$ \\
\hline $\begin{array}{l}\mathrm{R}^{2} \\
\text { Log likelihood }\end{array}$ & $\begin{array}{r}0.149 \\
-3,662.5\end{array}$ & $-3,622.2$ & $\begin{array}{r}\cdots \\
-3,614.2\end{array}$ \\
\hline \multicolumn{4}{|l|}{ Ages $70-84^{\mathrm{b}}$} \\
\hline Constant & $\begin{array}{l}61.710 \\
(0.904)\end{array}$ & $\begin{array}{l}61.904 \\
(0.955)\end{array}$ & $\begin{array}{l}61.976 \\
(1.136)\end{array}$ \\
\hline Retiree health insurance & $\begin{array}{r}-1.471 \\
(0.269)\end{array}$ & $\begin{array}{r}-1.522 \\
(0.277)\end{array}$ & $\begin{array}{c}-1.307 \\
(0.287)\end{array}$ \\
\hline Education & $\begin{array}{c}0.157 \\
(0.041)\end{array}$ & $\begin{array}{c}0.162 \\
(0.042)\end{array}$ & $\begin{array}{c}0.158 \\
(0.048)\end{array}$ \\
\hline Black & $\begin{array}{c}0.363 \\
(0.476)\end{array}$ & $\begin{array}{c}0.382 \\
(0.490)\end{array}$ & $\begin{array}{c}0.410 \\
(0.490)\end{array}$ \\
\hline $\begin{array}{l}\mathrm{R}^{2} \\
\text { Log likelihood }\end{array}$ & $\begin{array}{r}0.113 \\
-2,538.0\end{array}$ & $-2,532.8$ & $\begin{array}{r}\cdots \\
-2,526.2\end{array}$ \\
\hline
\end{tabular}

Source: Author's regressions using data from the 1987 National Medical Expenditure Survey.

a. The dependent variable is age at retirement. All specifications include a complete set of cohort dummies. Standard errors are in parentheses.

b. The full sample consists of 1,539 men, aged 55-84, who reported ever having retired. There are 1,359 men who are aged 65 and older and 1,006 men aged 70 and older. 
subject to the truncation bias discussed earlier because age at retirement is observed only for those who have actually retired. These coefficients are presented for the sake of comparison with the coefficients in the second column, in which the truncation is explicitly accounted for in the estimation. The first column of the top section, which uses the full sample, shows that in the ordinary least squares specification retiree health insurance reduces the age at retirement by a little more than a year. This effect is statistically significant with a $t$-statistic of 6.7. Education has a positive and significant effect on the age at retirement, with an additional year of school increasing the retirement age by about a month. Being black has a positive but insignificant effect on the age at retirement.

Explicitly accounting for the truncation in the data, as is done in the second column, increases the magnitude of all the coefficients. This is consistent with the notion that truncation leads to a downward bias in the coefficients. The impact of retiree health insurance on the age at retirement is about 20 percent greater in the truncated regression than under ordinary least squares, reducing the age at retirement by 1.4 years. Not surprisingly, a specification test rejects ordinary least squares in favor of the truncated regression model. ${ }^{44}$

To further illustrate the effects of truncation, the next two sections of table 5 restrict the sample to older ages: those aged 65 and older and those aged 70 and older. The substantial increase in the coefficients on retiree health insurance in the first column confirms the assertion that the truncation in the data leads to biased coefficients when using ordinary least squares. The problem with truncation is less severe at older ages and, as expected, the ordinary least squares and truncated regression coefficients are less disparate in the 65-84 sample than in the full sample. When the sample is restricted to ages $70-84$, the two sets of coefficients are very similar, although the likelihood ratio test still rejects the ordinary least squares model in favor of the truncated regression model. The effect of retiree health insurance increases slightly when the

44. The test whether the truncation in the data creates a substantial bias in the ordinary least squares coefficient estimates is a test of the significance of the inverse Mill's ratio $[-\phi(\alpha) / \Phi(\alpha)]$ in the ordinary least squares regression

$$
y_{i}=\beta^{\prime} \mathbf{x}_{i}+\gamma R H I_{i}+\delta \frac{\phi\left(\alpha_{i}\right)}{\Phi\left(\alpha_{i}\right)}+\epsilon_{i},
$$

where $\alpha_{i}=\left(a g e_{i}-\beta^{\prime} \mathbf{x}_{i}-\gamma R H I_{i}\right) / \sigma$. In this regression, the $t$-statistic on the coefficient $\delta$ equals 3.57 , which suggests that the truncation does indeed matter. 
sample is restricted to this older group, reducing the age at retirement by about 1.5 years.

To the extent that the bias associated with truncation is remedied by explicitly accounting for it in the estimation, the increase in the retiree health insurance coefficient in the second column, as the sample is restricted to older ages, is consistent with the notion that differential mortality leads to an upward bias in the coefficients, a problem that would be more severe in an older sample. However, the effect of retiree health insurance is only slightly larger when the sample is confined to those aged $70-84$ relative to that obtained using the full sample, suggesting that the size of the mortality bias is not large.

One concern with interpreting the coefficient on retiree health insurance in these specifications is that the model omits many variables that may be correlated with retiree health insurance. Chief among them is pensions. As table 3 showed, the industries that tend to offer retiree health insurance also tend to offer pensions. However, as noted previously, none of the data sets with good health insurance information contains the detailed data on pension incentives that would be helpful in a retirement model. The NMES, with absolutely no information on pensions, is the worst offender.

The third column of table 5 attempts to partially address this concern by including a set of industry and occupation dummies in the truncated regression model. Not surprisingly, the coefficient on retiree health insurance falls when industry and occupation controls are present. The effect of retiree health insurance, however, is still large and statistically significant, reducing the age at retirement by 1.3 years for the two subsamples. These results suggest, therefore, that there is a significant correlation between the availability of retiree health insurance and early retirement. In the two subsamples, those with retiree health insurance retire about 16 months before those without retiree health insurance, even after controlling for industry and occupation, which are likely correlated with other pension incentives that similarly encourage early retirement.

Table 6 presents results analogous to those in table 5 using the SIPPEWH sample. Once again, the effects of truncation are readily apparent. For the full sample, the coefficient on retiree health insurance is -0.39 under ordinary least squares and -0.63 in the truncated regression model. In both cases, these effects are significant, although they are sub- 
Table 6. Postretirement Health Insurance and the Age at Retirement (SIPP-EWH) ${ }^{\mathrm{a}}$

\begin{tabular}{|c|c|c|c|}
\hline \multirow{2}{*}{$\begin{array}{c}\text { Age group, } \\
\text { independent variable, } \\
\text { and summary statistic }\end{array}$} & \multirow[b]{2}{*}{$\begin{array}{l}\text { Ordinary least } \\
\text { squares }\end{array}$} & \multicolumn{2}{|c|}{ Truncated regression } \\
\hline & & $\begin{array}{c}\text { Full } \\
\text { sample }\end{array}$ & $\begin{array}{c}\text { Those with } \\
\text { pension income }\end{array}$ \\
\hline \multicolumn{4}{|l|}{ Ages $55-84^{\mathrm{b}}$} \\
\hline Constant & $\begin{array}{l}56.143 \\
(0.552)\end{array}$ & $\begin{array}{l}66.627 \\
(1.798)\end{array}$ & $\begin{array}{l}63.307 \\
(1.668)\end{array}$ \\
\hline Retiree health insurance & $\begin{array}{r}-0.388 \\
(0.183)\end{array}$ & $\begin{array}{r}-0.627 \\
(0.275)\end{array}$ & $\begin{array}{r}-0.634 \\
(0.294)\end{array}$ \\
\hline Education & $\begin{array}{c}0.080 \\
(0.024)\end{array}$ & $\begin{array}{c}0.115 \\
(0.035)\end{array}$ & $\begin{array}{c}0.109 \\
(0.041)\end{array}$ \\
\hline Black & $\begin{array}{c}0.163 \\
(0.330)\end{array}$ & $\begin{array}{c}0.314 \\
(0.490)\end{array}$ & $\begin{array}{c}1.145 \\
(0.556)\end{array}$ \\
\hline $\begin{array}{l}\mathrm{R}^{2} \\
\text { Log likelihood } \\
\text { Sample size }\end{array}$ & $\begin{array}{r}0.348 \\
-5,524.2 \\
2,009\end{array}$ & $\begin{array}{r}\cdots \\
-5,209.2 \\
2,009\end{array}$ & $\begin{array}{r}\cdots \\
-2,833.0 \\
1,146\end{array}$ \\
\hline \multicolumn{4}{|l|}{ Ages $65-84$} \\
\hline Constant & $\begin{array}{l}60.870 \\
(0.543)\end{array}$ & $\begin{array}{l}64.139 \\
(0.936)\end{array}$ & $\begin{array}{l}62.843 \\
(0.992)\end{array}$ \\
\hline Retiree health insurance & $\begin{array}{r}-0.586 \\
(0.221)\end{array}$ & $\begin{array}{r}-0.794 \\
(0.291)\end{array}$ & $\begin{array}{r}-0.697 \\
(0.309)\end{array}$ \\
\hline Education & $\begin{array}{c}0.094 \\
(0.029)\end{array}$ & $\begin{array}{c}0.123 \\
(0.037)\end{array}$ & $\begin{array}{c}0.129 \\
(0.043)\end{array}$ \\
\hline Black & $\begin{array}{c}0.278 \\
(0.392)\end{array}$ & $\begin{array}{c}0.402 \\
(0.518)\end{array}$ & $\begin{array}{c}1.211 \\
(0.589)\end{array}$ \\
\hline $\begin{array}{l}\mathrm{R}^{2} \\
\text { Log likelihood } \\
\text { Sample size }\end{array}$ & $\begin{array}{r}0.198 \\
-4,610.7 \\
1,630\end{array}$ & $\begin{array}{r}\cdots \\
-4,482.5 \\
1,630\end{array}$ & $\begin{array}{r}\cdots \\
-2,351.1 \\
891\end{array}$ \\
\hline $\begin{array}{l}\text { Ages } 70-84 \\
\text { Constant }\end{array}$ & $\begin{array}{l}62.760 \\
(0.611)\end{array}$ & $\begin{array}{l}63.805 \\
(0.753)\end{array}$ & $\begin{array}{l}63.570 \\
(0.851)\end{array}$ \\
\hline Retiree health insurance & $\begin{array}{r}-1.084 \\
(0.313)\end{array}$ & $\begin{array}{r}-1.249 \\
(0.356)\end{array}$ & $\begin{array}{r}-1.087 \\
(0.383)\end{array}$ \\
\hline Education & $\begin{array}{c}0.112 \\
(0.039)\end{array}$ & $\begin{array}{c}0.127 \\
(0.044)\end{array}$ & $\begin{array}{c}0.149 \\
(0.053)\end{array}$ \\
\hline Black & $\begin{array}{c}0.375 \\
(0.549)\end{array}$ & $\begin{array}{c}0.428 \\
(0.630)\end{array}$ & $\begin{array}{c}1.056 \\
(0.695)\end{array}$ \\
\hline $\begin{array}{l}\mathrm{R}^{2} \\
\text { Log likelihood } \\
\text { Sample size }\end{array}$ & $\begin{array}{r}0.137 \\
-3,166.0 \\
1,076\end{array}$ & $\begin{array}{r}\cdots \\
-3,136.2 \\
1,076\end{array}$ & $\begin{array}{r}\cdots \\
-1,569.2 \\
561\end{array}$ \\
\hline
\end{tabular}

Source: Author's regressions using data from the 1984 Survey of Income and Program Participation (wave 3) for men who participated in the Education and Work History module (SIPP-EWH).

a. The dependent variable is age at retirement. All specifications include a complete set of cohort dummies. Standard errors are in parentheses.

b. The full sample consists of men aged 55-84 who did not work during the quarter preceding the survey. 
stantially lower than those obtained from the NMES. The coefficients become larger, however, as the sample is restricted to older ages, and the coefficient in the truncated regression model for those aged 70-84 is close to that obtained in the NMES $(-1.25$ versus -1.52$)$. This suggests that, in this sample, either the truncated regression model may not be completely capturing the effects of the truncation or the bias resulting from differential mortality is greater than in the NMES. The true effect probably lies somewhere between the -0.63 coefficient obtained from the truncated regression on the full sample and the -1.25 coefficient obtained from the sample restricted to those aged 70-84.

The third column of table 6 restricts the sample to those who are receiving pension income. This is done both to enhance comparability with the SIPP-CJR sample, which includes only those with pension income, and to control for the effect of pensions. This restriction on the sample does not substantively change the coefficients. Note that when the sample is confined to those who are receiving a pension, the effect of retiree health insurance cannot be entirely attributed to an omitted pension bias. Even among those with pensions, having retiree health insurance decreases the age at retirement by 7 to 12 months.

Results using the SIPP-CJR sample are presented in table 7. Once again, the truncated regression coefficients on retiree health insurance are larger than the ordinary least squares coefficients and increase slightly as the sample is restricted to older ages. When industry and occupation dummies are included, the coefficients imply a reduction in the age at retirement of five to six months, a result smaller than that using the NMES data but consistent with that from the SIPP-EWH sample. Because this sample is composed entirely of individuals receiving a pension, these results are less likely to be subject to an omitted pension bias. Industry and occupation controls are added in the third column. The industry and occupation codes in the CJR topical module are not available in the 1984 panel of the SIPP, so the sample in the third column of table 7 is confined to those in the 1985 and 1986 panels of the SIPP; sample sizes are thus substantially smaller than in the first two columns. When industry and occupation controls are included, the coefficient on retiree health insurance falls somewhat, although it remains marginally significant, and implies a reduction in the age at retirement of five months.

An alternative approach to examining the effect of health insurance on retirement would be to estimate the effect of retiree health insur- 
Table 7. Postretirement Health Insurance and the Age at Retirement (SIPP-CJR) ${ }^{\mathrm{a}}$

\begin{tabular}{|c|c|c|c|}
\hline \multirow[b]{2}{*}{$\begin{array}{c}\text { Age group, } \\
\text { independent variable, } \\
\text { and summary statistic }\end{array}$} & \multirow{2}{*}{$\begin{array}{c}\text { Ordinary } \\
\text { least squares } \\
\text { No industry and } \\
\text { occupation } \\
\text { dummies }\end{array}$} & \multicolumn{2}{|c|}{ Truncated regression } \\
\hline & & $\begin{array}{l}\text { No industry and } \\
\text { occupation } \\
\text { dummies }\end{array}$ & $\begin{array}{l}\text { Industry and } \\
\text { occupation } \\
\text { dummies }\end{array}$ \\
\hline \multicolumn{4}{|l|}{ Ages $55-84^{\mathrm{b}}$} \\
\hline Constant & $\begin{array}{l}56.797 \\
(0.479)\end{array}$ & $\begin{array}{c}63.177 \\
(1.153)\end{array}$ & $\begin{array}{c}62.896 \\
(1.718)\end{array}$ \\
\hline Retiree health insurance & $\begin{array}{r}-0.570 \\
(0.150)\end{array}$ & $\begin{array}{r}-0.723 \\
(0.193)\end{array}$ & $\begin{array}{r}-0.451 \\
(0.256)\end{array}$ \\
\hline Education & $\begin{array}{c}0.017 \\
(0.021)\end{array}$ & $\begin{array}{c}0.022 \\
(0.027)\end{array}$ & $\begin{array}{c}0.021 \\
(0.043)\end{array}$ \\
\hline Black & $\begin{array}{c}0.528 \\
(0.292)\end{array}$ & $\begin{array}{c}0.734 \\
(0.395)\end{array}$ & $\begin{array}{c}0.345 \\
(0.566)\end{array}$ \\
\hline $\mathbf{R}^{2}$ & 0.271 & $\ldots$ & $\ldots$ \\
\hline Log likelihood & $-5,864.5$ & $-5,582.4$ & $-3,132.4$ \\
\hline Sample size & 2,243 & 2,243 & 1,210 \\
\hline \multicolumn{4}{|l|}{ Ages $65-84$} \\
\hline Constant & $\begin{array}{l}61.767 \\
(0.454)\end{array}$ & $\begin{array}{l}63.749 \\
(0.636)\end{array}$ & $\begin{array}{l}63.971 \\
(1.069)\end{array}$ \\
\hline Retiree health insurance & $\begin{array}{r}-0.687 \\
(0.173)\end{array}$ & $\begin{array}{c}-0.793 \\
(0.200)\end{array}$ & $\begin{array}{r}-0.514 \\
(0.267)\end{array}$ \\
\hline Education & $\begin{array}{c}0.027 \\
(0.025)\end{array}$ & $\begin{array}{c}0.031 \\
(0.028)\end{array}$ & $\begin{array}{c}0.021 \\
(0.046)\end{array}$ \\
\hline Black & $\begin{array}{c}0.794 \\
(0.358)\end{array}$ & $\begin{array}{c}0.945 \\
(0.421)\end{array}$ & $\begin{array}{c}0.715 \\
(0.612)\end{array}$ \\
\hline $\mathrm{R}^{2}$ & 0.110 & $\cdots$ & $\cdots$ \\
\hline Log likelihood & $-4,770.6$ & $-4,694.7$ & $-2,538.5$ \\
\hline Sample size & 1,784 & 1,784 & 971 \\
\hline \multicolumn{4}{|l|}{ Ages 70-84 } \\
\hline Constant & $\begin{array}{l}63.013 \\
(0.491)\end{array}$ & $\begin{array}{c}63,330 \\
(0.524)\end{array}$ & $\begin{array}{l}63.114 \\
(1.046)\end{array}$ \\
\hline Retiree health insurance & $\begin{array}{r}-0.819 \\
(0.231)\end{array}$ & $\begin{array}{r}-0.854 \\
(0.240)\end{array}$ & $\begin{array}{r}-0.415 \\
(0.311)\end{array}$ \\
\hline Education & $\begin{array}{c}0.039 \\
(0.032)\end{array}$ & $\begin{array}{c}0.040 \\
(0.033)\end{array}$ & $\begin{array}{r}-0.002 \\
(0.054)\end{array}$ \\
\hline Black & $\begin{array}{c}1.067 \\
(0.484)\end{array}$ & $\begin{array}{c}1.127 \\
(0.506)\end{array}$ & $\begin{array}{c}0.909 \\
(0.730)\end{array}$ \\
\hline $\mathrm{R}^{2}$ & 0.075 & $\ldots$ & $\ldots$ \\
\hline Log likelihood & $-3,211.4$ & $-3,203.3$ & $-1,760.1$ \\
\hline Sample size & 1,163 & 1,163 & 649 \\
\hline
\end{tabular}

Source: Author's regressions using data from the Survey of Income and Program Participation for men who participated in the Characteristics of Job from Which Retired module (SIPP-CJR).

a. The dependent variable is age at retirement. All specifications include a complete set of cohort dummies. Standard errors are in parentheses.

b. The full sample consists of men aged 55-84 who report receiving pension income. 
Table 8. Postretirement Health Insurance and the Probability of Early Retirement ${ }^{\mathrm{a}}$

\begin{tabular}{lccc}
\hline & National Medical & \multicolumn{2}{c}{$\begin{array}{c}\text { Survey of Income and } \\
\text { Program Participation }\end{array}$} \\
\cline { 3 - 4 } and summentent variable & $\begin{array}{c}\text { Expenditure } \\
\text { Survey }\end{array}$ & 0.389 & CJR \\
\hline Constant & 1.220 & $(0.169)$ & 0.605 \\
Retiree health insurance & $(0.329)$ & 0.202 & $(0.166)$ \\
Education & 0.428 & $(0.087)$ & 0.173 \\
& $(0.089)$ & -0.014 & $-0.079)$ \\
Black & -0.051 & $(0.011)$ & $(0.011)$ \\
& $(0.014)$ & -0.100 & -0.410 \\
Log likelihood & -0.240 & $(0.151)$ & $(0.159)$ \\
Sample size & $(0.158)$ & 707.7 & -733.4 \\
\hline
\end{tabular}

Source: Author's regressions using data from the 1987 NMES and the two supplements to the SIPP.

a. The table presents results from estimating a probit equation for whether an individual retired before age 65 . The sample consists of men aged 70-84. All specifications include a complete set of cohort dummies. Standard errors are in parentheses.

ance on the likelihood of "early" retirement. In the retirement literature, "early" typically refers to retirement before age 65 , the "normal" retirement age according to social security policies. Age 65 is also a natural breakpoint because this is the age at which individuals become eligible for Medicare.

The results from estimating a probit equation for whether an individual retires before age 65 are shown in table 8 . Because truncation is still an issue, the sample is restricted to individuals aged 70-84. The sign on the retiree health insurance coefficient is positive because health insurance now serves to increase the likelihood of early retirement (whereas in the previous three tables it decreased the age at retirement). The results in the first column, using the NMES data, suggest that retiree health insurance increases the probability of early retirement by about 15 percentage points. ${ }^{45}$ For the SIPP-EWH sample in the second column, the coefficient on retiree health insurance implies an increase in the probability of early retirement of approximately 7.5 percentage points. Although not shown, this effect does not appear to differ on the basis of receiving pension income. These results are similar to those in

45. The increase in the probability is calculated as the average across all individuals in the sample of the difference between the predicted probabilities of early retirement with and without retiree health insurance. 
Table 9. Differences in Pensions for Those with and without Retiree Health Insurance Dollars or percent

\begin{tabular}{|c|c|c|c|c|}
\hline \multirow[b]{2}{*}{ Pension characteristic } & \multicolumn{2}{|c|}{ Full sample } & \multicolumn{2}{|c|}{ Ages $70-84$} \\
\hline & $\begin{array}{l}\text { With } \\
\text { retiree health } \\
\text { insurance }\end{array}$ & $\begin{array}{l}\text { Without } \\
\text { retiree health } \\
\text { insurance }\end{array}$ & $\begin{array}{l}\text { With } \\
\text { retiree health } \\
\text { insurance }\end{array}$ & $\begin{array}{l}\text { Without } \\
\text { retiree health } \\
\text { insurance }\end{array}$ \\
\hline $\begin{array}{l}\text { Average social security } \\
\text { amount }\end{array}$ & 545 & 552 & 555 & 559 \\
\hline Average pension amount & 761 & 424 & 616 & 363 \\
\hline $\begin{array}{l}\text { Percent that received } \\
\text { cost-of-living adjustment }\end{array}$ & 51.4 & 35.0 & 67.1 & 41.6 \\
\hline $\begin{array}{l}\text { Percent with defined } \\
\text { contribution plan }\end{array}$ & 8.9 & 13.3 & 10.2 & 13.9 \\
\hline
\end{tabular}

Source: Author's calculations based on the Survey of Income and Program Participation (SIPP-CJR).

a. The full sample includes men aged 55-84 who reported receiving pension income.

the column for the SIPP-CJR sample in which the coefficient implies that retiree health insurance increases the probability of retirement by about 6 percentage points.

Overall, the results in tables 5-8 support the conclusion that retiree health insurance is a strong predictor of early retirement. Having such health insurance significantly increases the probability of retiring before age 65 . It also decreases the age at retirement by between 6 and 14 months, although taken together the coefficients suggest an effect of about 1 year.

\section{Pensions and Retiree Health Insurance}

The result that retiree health insurance has a significant negative impact on age at retirement even among those receiving pensions lends some support to the argument that the effect of retiree health insurance is not simply a pension effect; however, the evidence is by no means conclusive. It is possible that, within the set of firms that provide pensions, those who provide retiree health insurance have pension incentives that induce early retirement as well. Without information on the specific details of these pension plans, I cannot directly test for this. I can, however, examine whether the pensions received by individuals with retiree health insurance are different.

Table 9 presents some summary statistics on the pension benefits and 
social security payments received by individuals in the SIPP-CJR sample (all of whom have pensions). The first row shows that average social security payments received by individuals with retiree health insurance are virtually identical to those received by individuals without retiree health insurance. Although social security is not a perfect indicator of preretirement income (and is somewhat endogenous to the decision of when to retire), these numbers suggest that the wage component of compensation is similar for jobs with and without retiree health insurance.

The nonwage component of compensation, however, may be quite different. The second row of table 9 shows that the average pension received by individuals with retiree health insurance is $\$ 250-\$ 350$ higher than that received by individuals without retiree health insurance. Moreover, individuals with retiree health insurance are more likely to have received a cost-of-living adjustment to their pension (which partially accounts for the difference in pension amounts in the second row). These last two findings suggest that firms that offer retiree health insurance provide more generous pension benefits as well.

One possible way to skirt the problem of whether firms that provide retiree health insurance also provide pension incentives for early retirement is to look at individuals who participated in defined contribution plans. The SIPP-CJR data record whether a retiree's pension was based on "years of service and pay" (defined benefit) or on the "amount contributed to [the] plan" (defined contribution). Defined contribution plans do not typically include the incentives for retirement at particular ages characteristic of many defined benefit plans. ${ }^{46}$

Table 10 compares the effect of retiree health insurance on age at retirement for those in defined benefit and defined contribution plans. While the coefficient on retiree health insurance is negative and significant for those in defined benefit pension plans, it is positive and significant for those in defined contribution plans (despite a 90 percent reduction in sample size). This result is somewhat troubling. It is difficult to believe that retiree health insurance actually increases the age at retirement by almost 18 months.

There are at least two interpretations of this surprising result. The first is that health insurance does not really affect retirement and that the coefficient on retiree health insurance estimated for those with defined

46. Samwick (1993a). 
Table 10. Postretirement Health Insurance, the Age at Retirement, and Pensions ${ }^{\mathrm{a}}$

\begin{tabular}{lcc}
\hline $\begin{array}{c}\text { Independent variable } \\
\text { and summary statistic }\end{array}$ & $\begin{array}{c}\text { Defined benefit } \\
\text { pension }\end{array}$ & $\begin{array}{c}\text { Defined contribution } \\
\text { pension }\end{array}$ \\
\hline Constant & 62.761 & 59.943 \\
Retiree health insurance & $(0.881)$ & $(3.162)$ \\
& -0.648 & 1.433 \\
Education & $(0.186)$ & $(0.580)$ \\
& 0.004 & 0.139 \\
Black & $(0.025)$ & $(0.081)$ \\
& 0.299 & 3.014 \\
Log likelihood & $(0.376)$ & $(1.096)$ \\
Sample size & $-5,807.8$ & -680.8 \\
\end{tabular}

Source: Author's regressions using data from the Survey of Income and Program Participation (SIPP-CJR). The sample includes men aged 55-84 who reported receiving pension income.

a. The table presents results from estimating a truncated regression model in which the dependent variable is the age at retirement. All specifications include a complete set of cohort dummies. Standard errors are in parentheses.

benefit pension plans is purely a pension effect. However, even if it is true that firms offering retiree health insurance also offer defined benefit pension plans that encourage early retirement, why should these particular firms offer retiree health insurance? If the answer is that firms can make the early retirement incentives in their pensions operative only by offering retiree health insurance, then health insurance matters in the retirement decision even if its provision is correlated with pension benefits.

A second interpretation of the positive retiree health insurance coefficient for those with defined contribution pensions is that it is picking up the fact that those firms that provide retiree health insurance are "better" employers, and individuals are therefore more likely to defer retirement. To the extent that this bias is present in the previously presented empirical work, it makes the negative coefficient on retiree health insurance in all the other specifications more striking.

The right conclusion to draw from table 10, however, is that further research on the relationship between pensions and retiree health insurance is warranted. Little is known about how firms design their compensation packages. To the extent that firms design their benefits packages to meet certain objectives, such as early retirement, understanding the correlation between types of benefits is important. Integrating pensions, health insurance, wages, and other forms of compensation into the re- 
tirement decision is the next step in evaluating how health insurance affects retirement.

\section{Assessing the Effect of Health Insurance on Retirement}

Previous cautions aside, this section of the paper uses the estimates derived earlier of the effect of retiree health insurance on the age at and probability of early retirement to answer three important questions. The first question, of great interest to both policymakers and academic researchers, is what will be the impact of health care reform on retirement? Although the empirical work in this paper can be used only to address the possible supply responses, I discuss other responses that may occur as well. The second question is the extent to which the increased availability of retiree health insurance can explain the decreasing labor force participation of older workers over the past few decades. Previous work on pensions and social security suggests that, together, they explain between one-third and one-half of this decline; the results in this paper suggest that retiree health insurance may be responsible for another 10 to 20 percent. Finally, I examine whether the availability of Medicare can explain the "excess" retirement that occurs at age 65. I find little evidence that Medicare is important.

\section{Impact of Health Care Reform on Retirement}

Given the current interest in health care reform, what implications can be drawn from the results in this paper about the potential labor market effects of the various proposals? The most natural reform to consider would be a move to universal health care. Table 11 illustrates the consequences of such a step based on the assumption that universal health care would reduce the retirement age of those currently without retiree health insurance by one year. ${ }^{47}$ The effect on the labor force participa-

47. The effect on the labor force participation rate in table 11 is computed as follows. I calculated the actual distribution of retirement ages for individuals over age 70 in the NMES data with and without retiree health insurance and the age-specific labor force participation rates that these distributions implied. I then shifted the retirement age distribution forward by one year for those without retiree health insurance and recalculated the labor force participation rate. The decline in the labor force participation rate was then recalibrated to be consistent with the official labor force participation rate published in U.S. Bureau of Labor Statistics, Employment and Earnings, June 1987 (which is reported in the third column of table 11). 
Table 11. Effect of Universal Coverage on Labor Force Participation Units as indicated

\begin{tabular}{|c|c|c|c|c|}
\hline \multirow[b]{2}{*}{ Age } & \multirow{2}{*}{$\begin{array}{c}\text { Male } \\
\text { population } \\
\text { in 1987 } \\
\text { (millions) }\end{array}$} & \multirow{2}{*}{$\begin{array}{c}\text { Labor force } \\
\text { participation } \\
\text { rate } \\
\text { (percent) }\end{array}$} & \multicolumn{2}{|c|}{ Effect of universal coverage } \\
\hline & & & $\begin{array}{l}\text { Participation } \\
\text { rate (percent) }\end{array}$ & $\begin{array}{c}\text { Total } \\
\text { employment }\end{array}$ \\
\hline $50-54$ & 5.265 & 89.2 & -0.35 & $-18,541$ \\
\hline $55-59$ & 5.247 & 80.4 & -1.26 & $-65,875$ \\
\hline $60-64$ & 5.020 & 55.6 & -4.27 & $-214,181$ \\
\hline $65-69$ & 4.393 & 25.5 & -3.49 & $-153,267$ \\
\hline
\end{tabular}

Source: Author's calculations using data from the 1987 National Medical Expenditure Survey. See text for further details.

tion rate of men is shown in the third column and the absolute decline in employment in the fourth column. The effect is largest, both in percentage and absolute terms, for those aged 60-64. Universal coverage would reduce the labor force participation rate of this group by 4.27 percentage points, a 7.7 percent reduction from the baseline rate of 55.6 percent. The overall reduction in employment for men aged 50-69 would be about 450,000 . A more conservative estimate of the effect of retiree health insurance on retirement-for example, six months rather than a yearwould imply a smaller reduction in employment.

As noted in the introduction, the actual effects on retirement of any particular health care proposal will depend on the specific nature of the incentives contained in that proposal. The effects of employer-provided retiree health insurance estimated in this paper may therefore apply more readily to some plans than to others. The type of health insurance that would be available to early retirees under the Clinton plan is fairly similar to the employer-provided retiree health insurance examined in this paper. Under the Clinton plan, individuals between ages 55 and 64 who are not working are counted as early retirees. Since very few individuals retire before age 55, this type of "eligibility" requirement is not very restrictive and, if anything, is less likely to be binding than the eligibility requirements imposed by employers. The actual coverage under the Clinton plan is quite generous and on par with that offered by most large businesses. And, because the government subsidizes 80 percent of the cost for early retirees under the plan, the actual out-of-pocket cost to individuals is similar to that of most employer-provided retiree health insurance coverage, for which employers typically continue to pay a large part. 
While the numbers estimated in this paper give some measure of the likely supply response that would follow if generous low-cost health insurance coverage were made available to all early retirees, they may not give the actual change in the employment of older workers that would result if there were demand responses or other changes in the labor market as well. For example, some reform proposals would community-rate health insurance premiums. This implies that the young, with relatively low medical expenditures, would subsidize the premiums of those who are older. If employers must pay for some portion of health insurance premiums, then, for those employers who are now providing health insurance, community-rating will make older workers relatively less expensive to hire than under the current system in which employers pay the full health insurance costs of hiring older individuals. To the extent that this increases the demand for older workers, the effect of health care reform on the employment of older workers will be overstated.

For those employers who are not currently providing health insurance, requiring employers to pay for some portion of their employees' premiums may decrease the demand for older workers. The decreased demand, however, will depend on the degree to which the increased cost associated with paying for health insurance is offset by a decline in the wages that workers are willing to accept because they value the provision of health insurance. Empirical evidence on the effects of other mandates has concluded that most of the cost to employers of providing benefits shows up as lower wages and that the resulting employment effects are small. ${ }^{48}$ Survey evidence also suggests that individuals tend to give health insurance a higher value than the cost to employers of actually providing it ${ }^{49}$ This implies that workers would be willing to accept lower wages in return for employer payment of insurance premiums and that the change in employment at firms not currently providing health insurance is likely to be small.

The nature of retirement and labor force participation among older individuals may also change following reform. Many workers "par-

48. See Gruber and Krueger (1990), which examines the effect of workers' compensation insurance, and Gruber (1994), which looks at the effect of mandated maternity benefits.

49. The Employee Benefit Research Institute (1993) asked individuals how much extra wage compensation would induce them to give up their employer-provided health insurance. The mean response was $\$ 4,850$. In contrast, the average cost to firms of providing health insurance was $\$ 2,748$ per employee (Piacentini and Foley, 1992, p. 260). 
tially" retire, moving from full-time employment to part-time employment or self-employment before leaving the labor force entirely. The provision of subsidies only to those who are not working will discourage partial retirement, changing not only the timing of retirement but the process by which workers leave the labor force as well.

Finally, to the extent that firms design their compensation packages to meet certain objectives, changes in retirement behavior brought about by health care reform may induce firms to restructure the nature of other retirement incentives in ways that may either reinforce or offset this behavior. For example, if health care reform encourages early retirement among workers whom the firm would like to continue employing, the firm may change its pension plan in order to discourage this early retirement. While the possibility of this type of firm response makes evaluating the overall effects of health care reform on employment difficult, it serves to point out the many ways in which health insurance affects both individual and firm behavior.

\section{Does Retiree Health Insurance Explain the Trend toward Early \\ Retirement?}

Beyond the issue of the employment effects of health care reform, the results in this paper can also be used to address the question of how much of the persistent long-run trend toward early retirement can be explained by the increased availability of postretirement health insurance. Figure 5 shows the dramatic decline in the labor force participation of older men over the past three decades. In 1960, 34 percent of men over age 65 were working; by 1990 , this fraction had fallen to 16 percent. In absolute terms, the decline in labor force participation among men aged 60-64 is equally striking, falling from 82 percent in 1960 to 56 percent in 1990.

Part of this decline is due to changes in both social security and private pensions. Estimates of the effect of social security on retirement vary widely. Jerry Hausman and David Wise suggest that the 20-25 percent real increase in the value of social security benefits in the $1970 \mathrm{~s}$ could explain about 30 percent of the decline in labor force participation; Gary Burtless, however, estimates much smaller effects. ${ }^{50}$ More recent

50. See Hausman and Wise (1985) and Burtless (1986, p. 801). Quinn, Burkhauser, and Myers (1990) review the literature on the determinants of retirement. 
Figure 5. Labor Force Participation of Men, 1960-91

Percent in labor force

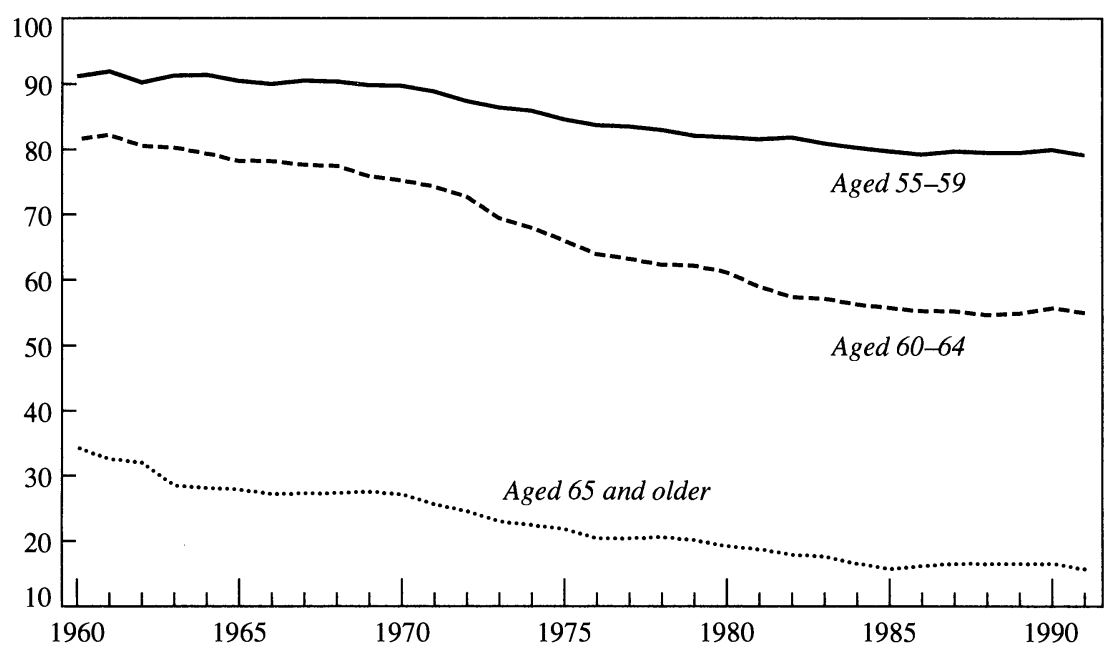

Source: U.S. Bureau of Labor Statistics, Employment and Earnings, various issues.

work has turned to estimating the effect of pension incentives on retirement. Andrew Samwick finds that growth in the availability of pensions accounts for 27 percent of the reduction in aggregate labor force participation. ${ }^{51}$ Together, therefore, pensions and social security explain between one-third and one-half of the decline in the labor force participation of older individuals.

As figures 2 and 3 show, the availability of employer-provided postretirement health insurance has also grown substantially over this time period. While about 25 percent of retirees in the 1960s had retiree health insurance, close to half of retirees in the 1980s had such coverage. The results of this paper suggest that retiree health insurance is associated with early retirement.

How much of the aggregate decline in labor force participation can be explained by the increased availability of retiree health insurance? The estimates in table 8 of the effect of retiree health insurance on the probability of early retirement can be used to answer this question. The results from the NMES data in the first column of table 8 imply that retiree health insurance increases the probability of early retirement by 15 per-

51. Samwick (1993b, p. 33). 
centage points; those from the two SIPP samples imply a somewhat smaller effect of about 7 percentage points. Figures 2 and 3 show that retiree health insurance was made available to an additional 25 percent of working men between 1960 and 1985 . The aggregate effect of retiree health insurance would therefore be a reduction of 1.75 to 3.75 percentage points in the probability of retirement before age $65(1.75=7 \times 0.25$, $3.75=15 \times 0.25)$. The overall reduction in the labor force participation rate of men aged 55-64 over this same time period was about 18 percentage points. This suggests that the increased availability of retiree health insurance can account for 10-21 percent of the aggregate reduction in the labor force participation of older men over the past three decades. This effect is within the range of estimates for social security discussed above and about half of the estimated effect arising from private pensions.

\section{Can Medicare Eligibility Explain the "Excess" Retirement at Age 65?}

Another natural question to ask is whether health insurance can explain the "excess" spike in the retirement hazard at age 65 , which exists even after accounting for financial incentives for retirement. ${ }^{52}$ To address this question directly, one would ideally like an estimate of how retiree health insurance affects the retirement hazard at each age. Although the data used in this paper do not lend themselves to the estimation of such a hazard, figure 6 plots the empirical hazard based on the actual retirement ages for each of the three data sets. I have not removed the effects of any of the other factors that influence retirement, but figure 6 is nonetheless illustrative of the differences in the hazard rates for those with and without retiree health insurance. ${ }^{53}$

Note that the overall shapes of the hazards are consistent with those in the previous literature and exhibit the characteristic spikes at ages 62 and 65 associated with social security eligibility. However, the shape is not markedly different for those with and without retiree health insur-

52. Lumsdaine, Stock, and Wise (forthcoming).

53. In particular, the removal of cohort effects could alter the hazards to the extent that older cohorts are both less likely to have retiree health insurance and less likely to have retired early for other reasons. The data, however, are too sparse to actually estimate a probability of retirement at each age that adequately controls for these and other effects. 
Figure 6. Probability of Early Retirement with and without Retiree Health Insurance Hazard
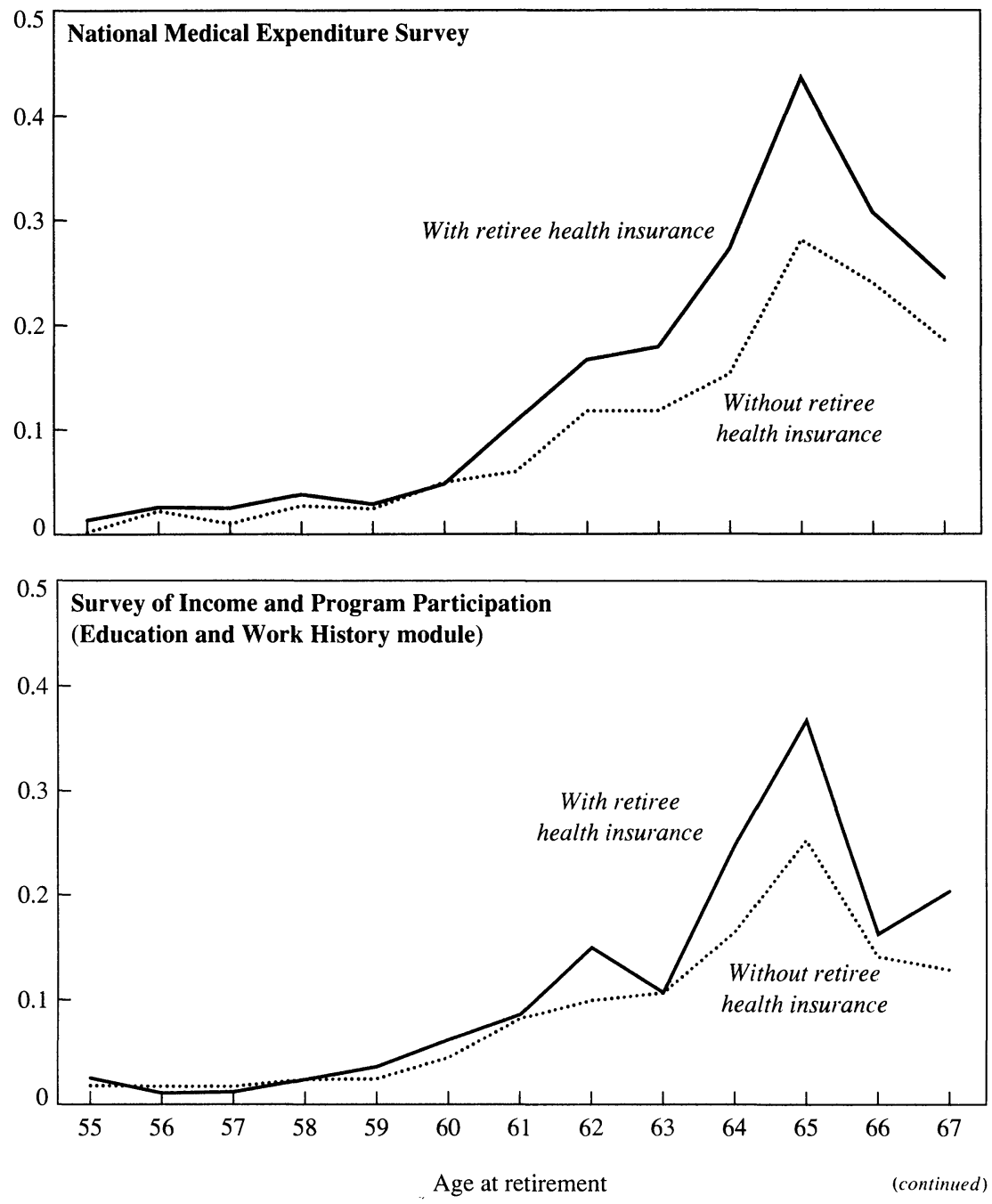

ance, and, in particular, the spike at age 65 is not diminished for those with retiree health insurance. In two of the three data sets, the spike at age 65 is actually larger for those with retiree health insurance. If entitlement to Medicare were a substantial explanation of the spike in the retirement hazard at age 65 , we would expect that individuals with retiree 
Figure 6 (continued)

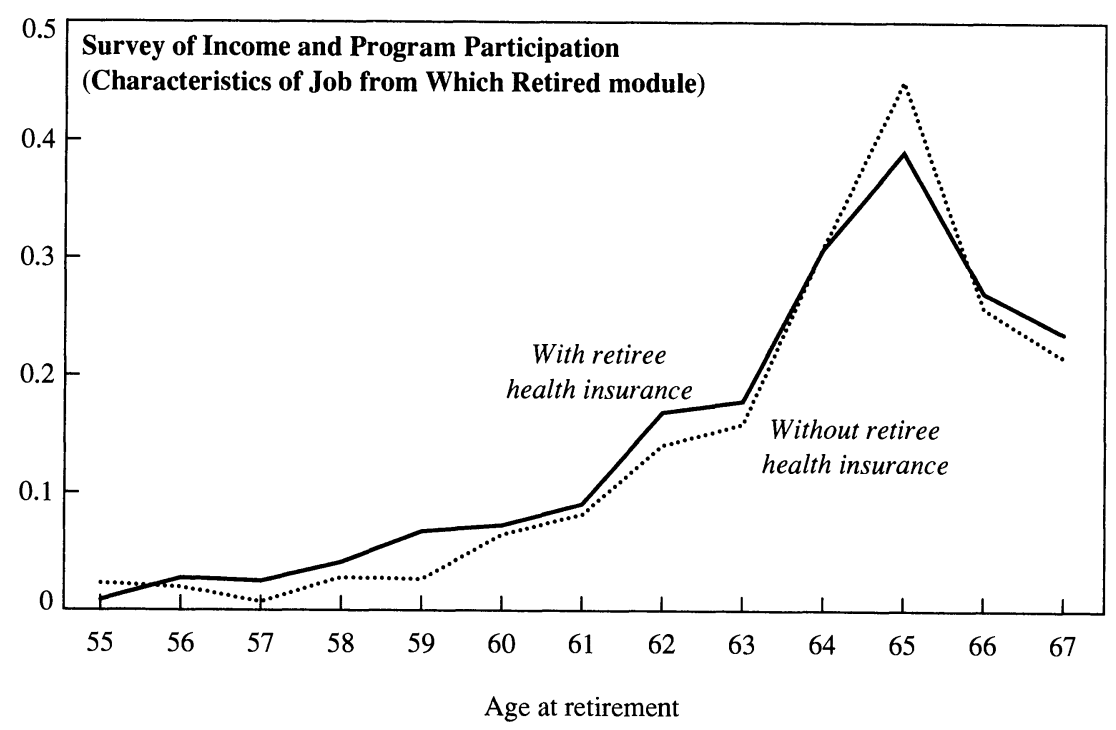

Source: Author's calculations using data from the 1987 NMES and the two supplements to the SIPP.

health insurance would not exhibit such a spike or, to the extent that the spike exists for other reasons (such as social security and pension incentives), it should be smaller for those with retiree health insurance.

To the extent that Medicare is inferior to employer-provided health insurance, this finding may not be quite so surprising. Employer-provided health insurance coverage is typically much more generous than Medicare. In 1989, only 6 percent of individuals covered by employerprovided health insurance in firms with 100 workers or more had deductibles above $\$ 300$ a year, while Medicare enrollees faced deductibles of $\$ 560$ for hospital stays of less than 60 days in addition to a $\$ 75$ annual physician deductible. While employer-provided health insurance almost always covers prescription drugs, Medicare does not. And while 70 percent of individuals with employer health insurance have their out-ofpocket expenditures limited to $\$ 1,500$ or less, Medicare has no out-ofpocket maximum. Overall, Medicare pays about 45 percent of the medical expenditures incurred by those over age $65 .{ }^{54}$ Given these

54. These figures on the generosity of both private health insurance and Medicare, as well as the fraction of expenditures paid by Medicare, come from Piacentini and Foley (1992, pp. 203, 267, 270, and 302). 
differences in coverage, individuals may simply place a sufficiently low value on Medicare that it provides no inducement to give up employerprovided health insurance upon reaching age 65 .

Medicare eligibility may also have little effect on retirement because spouses of those eligible for Medicare do not themselves receive coverage until they turn 65 . For those who are married with family coverage, giving up one's employer-provided health insurance upon retirement also implies giving up coverage for one's spouse. If individuals delay retirement to maintain their own health insurance coverage, it is also likely that they will delay retirement to maintain coverage for a spouse. With appropriate data, this is actually something one could test: among those with employer-provided retiree health insurance, does Medicare eligibility have a greater effect on retirement for those who are single and for those whose spouses have already reached age 65 ? Given the retrospective nature of the data used in this paper, this comparison is difficult to make since the spouses of individuals at the time of retirement may no longer be in the data, either because of death or divorce.

\section{Conclusion}

As the U.S. economy moves closer to health care reform, understanding the economic consequences of changing the way in which health care is financed and delivered is important for guiding policymakers as they shape the proposals for change. One area of the economy likely to be affected in significant ways is the labor market. This paper has discussed the various ways in which health insurance might influence both individual and firm behavior, focusing in particular on its effect on retirement.

I have examined the effect of employer-provided postretirement health insurance on both the age at retirement and the probability of early retirement. Using three different data sets, I found that individuals with retiree health insurance retire much earlier than individuals without such coverage. Estimates of this effect range from 5 to 16 months, although most of the coefficients point to an effect of about 1 year. I also found that retiree health insurance increases the probability of retiring before age 65 by between 7 and 15 percentage points. Both of these effects are sizable and suggest that individual retirement decisions are 
quite responsive to the availability of postretirement health insurance. Using these results to evaluate the likely effects of health care reform on the labor force participation of older individuals, I estimated that a move to universal coverage along the lines set forth in the Clinton health care proposal would reduce the labor force participation of men aged 60-64 by 4.3 percentage points.

While this effect is significant, it is important to realize that health care reform may affect the labor market for older workers in ways that may either increase or decrease employment. For example, communityrating of insurance premiums, a feature of many reform proposals, may lower the price to firms of hiring older workers, thereby increasing demand and partially offsetting the decrease in the labor supply estimated in this paper. Or, firms may change their pension incentives or other components of their compensation package in response to the changes in individual behavior induced by reform.

Beyond the issue of retirement, there are many other aspects of the labor market likely to be affected by changes in the provision of health insurance. The overall employment effects associated with health care reform will be determined not only by the retirement decisions of older workers but also by the labor force participation decisions of secondary earners, welfare participants, and the unemployed. In addition to its employment effects, health insurance may also matter for the structure of the labor market, influencing such things as job mobility, self-employment, and the demand for full-time versus part-time workers. While there is an emerging literature on many of these labor market effects, much research remains to be done before we can fully address the issue of how health insurance affects the labor market.

\section{APPENDIX}

\section{Data and Estimation}

THIS PAPER uses three different data sets to estimate the effect of employer-provided retiree health insurance on the age at retirement: the 1987 National Medical Expenditure Survey and two supplements to the Survey of Income and Program Participation. All three data sources contain information on whether an individual has retiree health insur- 
Table A1. Descriptive Statistics of Data

Units as indicated

\begin{tabular}{|c|c|c|c|c|c|c|}
\hline \multirow[b]{2}{*}{ Variable } & \multicolumn{2}{|c|}{$\begin{array}{c}\text { National Medical } \\
\text { Expenditure } \\
\text { Survey }\end{array}$} & \multicolumn{2}{|c|}{$\begin{array}{c}\text { Survey of Income } \\
\text { and Program } \\
\text { Participation } \\
(\text { EWH })\end{array}$} & \multicolumn{2}{|c|}{$\begin{array}{c}\text { Survey of Income } \\
\text { and Program } \\
\text { Participation } \\
\text { (CJR) }\end{array}$} \\
\hline & Mean & $\begin{array}{l}\text { Standard } \\
\text { deviation }\end{array}$ & Mean & $\begin{array}{l}\text { Standard } \\
\text { deviation }\end{array}$ & Mean & $\begin{array}{l}\text { Standard } \\
\text { deviation }\end{array}$ \\
\hline Age & 71.4 & 6.02 & 70.6 & 6.45 & 70.3 & 6.35 \\
\hline Age at retirement & 63.1 & 4.05 & 63.6 & 4.69 & 62.6 & 3.82 \\
\hline Black (percent) & 9.9 & 30.00 & 7.8 & 26.70 & 3.4 & 24.40 \\
\hline Education (years) & 11.0 & 3.41 & 10.2 & 3.70 & 11.1 & 3.49 \\
\hline Retiree health insurance (percent) & 46.0 & 49.90 & 39.7 & 48.90 & 63.8 & 48.10 \\
\hline Pension (percent) & . . & $\cdots$ & 57.0 & 49.50 & 100.0 & 0.00 \\
\hline \multicolumn{7}{|l|}{ Industry (percent) } \\
\hline Agriculture and construction ${ }^{\mathrm{a}}$ & 14.5 & 35.2 & $\ldots$ & $\ldots$ & 10.3 & 30.4 \\
\hline Manufacturing and transportation ${ }^{\mathrm{b}}$ & 46.7 & 49.9 & $\ldots$ & $\ldots$ & 55.6 & 49.7 \\
\hline Sales & 12.5 & 33.1 & $\ldots$ & . & 7.3 & 26.0 \\
\hline Financial and professional ${ }^{c}$ & 14.3 & 34.9 & $\cdots$ & $\cdots$ & 11.7 & 32.2 \\
\hline Public administration & 6.5 & 25.1 & $\ldots$ & $\cdots$ & 15.1 & 35.8 \\
\hline Unknown & 5.3 & 22.5 & $\ldots$ & $\ldots$ & $\cdots$ & $\cdots$ \\
\hline \multicolumn{7}{|l|}{ Occupation (percent) } \\
\hline Professional and technical ${ }^{\mathrm{d}}$ & 25.1 & 43.4 & $\ldots$ & $\ldots$ & 27.3 & 44.6 \\
\hline Sales and clerical & 14.3 & 35.0 & $\cdots$ & $\cdots$ & 13.3 & 33.9 \\
\hline Craftsmen and operators ${ }^{\mathrm{e}}$ & 45.9 & 49.8 & $\cdots$ & $\cdots$ & 49.5 & 50.0 \\
\hline Service & 7.1 & 25.7 & $\cdots$ & $\cdots$ & 9.4 & 29.2 \\
\hline Farm managers and laborers & 4.1 & 19.8 & $\ldots$ & $\ldots$ & 0.5 & 6.9 \\
\hline Unknown & 3.5 & 18.3 & $\cdots$ & $\ldots$ & $\cdots$ & $\cdots$ \\
\hline
\end{tabular}

Source: Author's calculations based on data from the 1987 NMES and two supplements to the SIPP. See text for details.
a. Also includes forestry and fishing.
b. Also includes communications, utilities, and repair services.
c. Also includes insurance, real estate, and personal services.
d. Also includes managerial and administrative workers.
e. Also includes transportation workers and laborers.

ance as well as the age at retirement. The data sets are described briefly in the text, and descriptive statistics are presented in table A1.

\section{Estimation}

Two types of retirement equations are estimated in the paper. The first is a basic ordinary least squares specification of the form

$$
y_{i}=\beta^{\prime} \mathbf{x}_{i}+\gamma R H I_{i}+\epsilon_{i}, \quad \epsilon_{i} \sim N\left(0, \sigma^{2}\right),
$$

where $y_{i}$ is age at retirement, $\mathbf{x}_{i}$ is a vector of demographic characteristics, and $R H_{i}$ is a dummy variable equal to one if the individual has re- 
Figure A1. Truncation of the Retirement Age Distribution

Observations

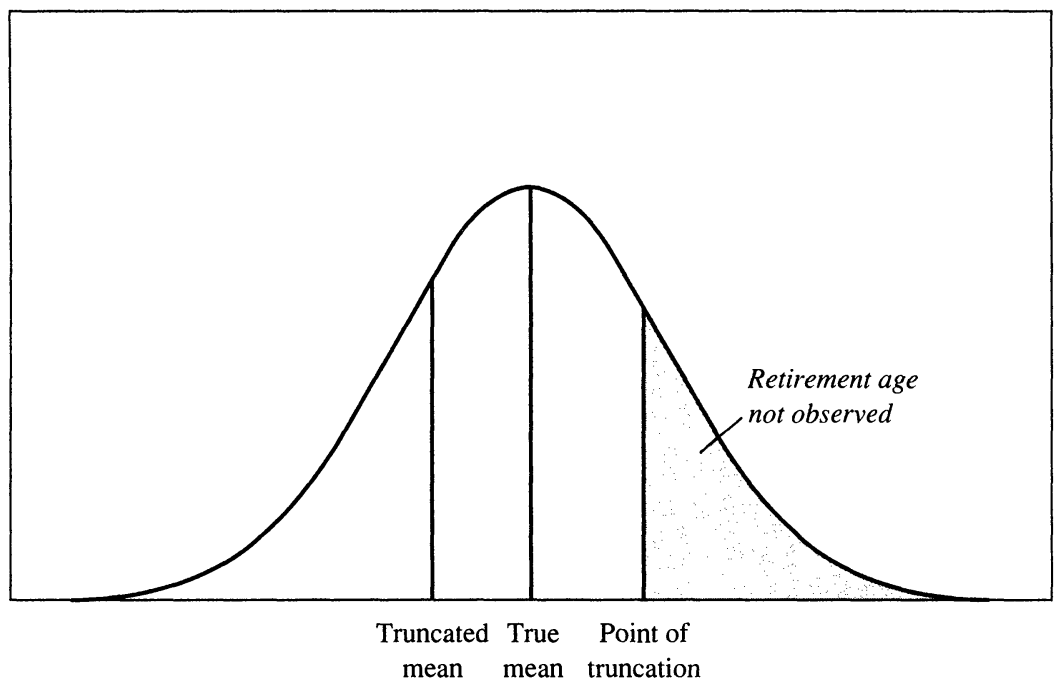

Age at retirement

tiree health insurance. As mentioned in the text, one problem with estimating this ordinary least squares specification is that in the data an individual's retirement age is observed only if that individual has retired (that is, one observes a conditional retirement age, $y_{i} \mid y_{i}<$ age $e_{i}$ ); retirement age is missing for all individuals who retire at an age greater than their current age. This is illustrated in figure A1. Those individuals in the shaded area of the distribution who have not yet retired will be excluded from the estimation because their retirement age is not yet known. As a result, the average retirement age measured in the sample of those actually retired (the truncated mean) will be less than the true population average observed if one knew the retirement age of everyone.

If retiree health insurance does indeed decrease the average age at retirement, this truncation will yield an estimate of the effect of retiree health insurance that is too small in an ordinary least squares regression. This is illustrated in figure A2. Because the retirement age distribution for those with retiree health insurance lies to the left of that for those without retiree health insurance, the sample truncation will be more severe among those without retiree health insurance. The difference be- 
Figure A2. Measuring the Effect of Retiree Health Insurance with Truncation Observations

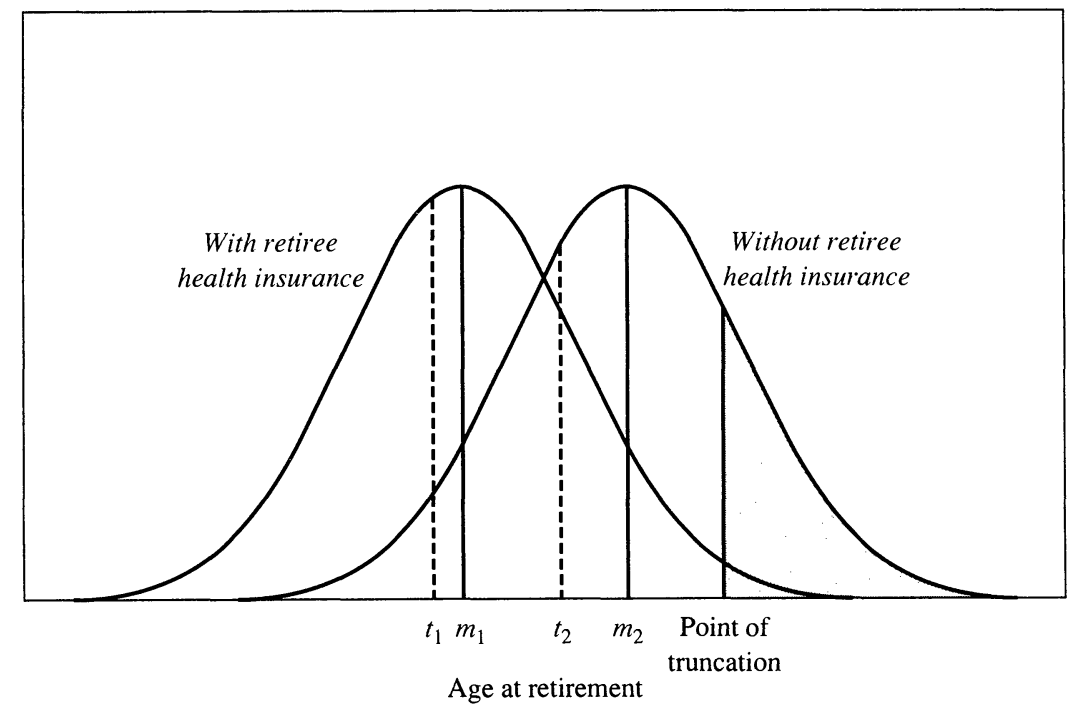

tween the true mean and the truncated mean retirement age will therefore be greater for those without retiree health insurance. While the true measure of $\gamma$ is given by $m_{1}-m_{2}$ (the difference between the true mean retirement ages of those with and without retiree health insurance), the estimate obtained from an ordinary least squares regression will equal $t_{1}-t_{2}$, the (smaller) difference between the truncated means.

The estimate of interest, however, is the effect of retiree health insurance on age at retirement in the population as a whole $\left(m_{1}-m_{2}\right)$, not just among those actually retired $\left(t_{1}-t_{2}\right)$. This estimate can be obtained by noting that the probability of an individual retiring at a particular age is given by the probability of retiring at that age conditional on retirement being observed, multiplied by the probability that the person is retired:

$$
P\left(y_{i}=Y\right)=P\left(y_{i}=Y \mid y_{i}<a g e_{i}\right) \times P\left(y_{i}<a g e_{i}\right) .
$$

Based on this formula, I estimate the unconditional effect of retiree health insurance on retirement using the truncated data in two different ways.

The first is to restrict the sample to those over age 70 , an age at which 
85 percent of individuals report being retired. With this restriction on the sample, the probability that an individual is retired $P\left(y_{i}<a g e_{i}\right)$ is close to one and the conditional effect estimated using ordinary least squares will not deviate too far from the unconditional effect. This procedure is somewhat unsatisfactory because it ignores all of the information on how retiree health insurance affects the retirement of younger cohorts. I therefore also estimate a standard truncated regression model that explicitly accounts for the truncation and can make use of the full sample of retired individuals. ${ }^{55}$ Note that if one is willing to make an assumption about the underlying distribution of the age at retirement, the part of the distribution that is observed can be used to infer the shape of the rest of the distribution. If the errors in equation A-1 are distributed normally with mean zero and variance $\sigma^{2}$, then the probability that an individual retires at a particular age $P\left(y_{i}=Y\right)$ in equation A-2 is simply $(1 / \sigma) \phi\left[\left(y_{i}\right.\right.$ $\left.\left.-\beta^{\prime} \mathbf{x}_{i}-\gamma R H I_{i}\right) / \sigma\right]$, while the probabilility of being retired and observed in the data, $P\left(y_{i}<a g e_{i}\right)$, equals $\Phi\left[\left(a g e_{i}-\beta^{\prime} \mathbf{x}_{i}-\gamma R H I_{i}\right) / \sigma\right]$, where $\phi$ is a normal density function and $\Phi$ is a cumulative normal distribution function. The conditional density function of the age at retirement given that an individual is actually retired, $P\left(y_{i} \mid y_{i}<a g e_{i}\right)$, is now that of a truncated normal:

$$
f\left(y_{i} \mid y_{i} \leq \operatorname{age}_{i}\right)=\frac{(1 / \sigma) \phi\left[\left(y_{i}-\beta^{\prime} \mathbf{x}_{i}-\gamma R H I_{i}\right) / \sigma\right]}{\Phi\left[\left(a g e_{i}-\beta^{\prime} \mathbf{x}_{i}-\gamma R H I_{i}\right) / \sigma\right]},
$$

which can be directly estimated. The corresponding log-likelihood function is given by

$$
\text { (A-4) } \begin{aligned}
\log L= & -N \log \left[(2 \pi)^{1 / 2} \sigma\right]-\frac{1}{2} \sum_{i}\left(\frac{y_{i}-\beta^{\prime} \mathbf{x}_{i}-\gamma R H I_{i}}{\sigma}\right)^{2}= \\
& -\sum_{i} \log \Phi\left(\frac{a g e_{i}-\beta^{\prime} \mathbf{x}_{i}-\gamma R H I_{i}}{\sigma}\right) .
\end{aligned}
$$

Note that the variance parameter, $\sigma^{2}$, is estimated along with $\beta$ and $\gamma$.

55. See Hausman and Wise (1977) and Maddala (1983). Note that it is not possible to estimate the more commonly used censored-regression model in this context because, for individuals who have not retired, the values of both the left- and some right-hand-side variables are missing; not only does one not observe a retirement age for those not yet retired but one also cannot infer whether these individuals have retiree health insurance until they retire. 


\section{Definition of Retirement}

As mentioned in the text, several different definitions of retirement have been used in the empirical literature on retirement, including (1) a "permanent" departure from the labor force, (2) a substantial reduction in the usual number of hours worked, (3) self-reported retirement, and (4) receipt of pension or social security benefits. Although the definition of retirement that could be examined in this paper was limited by the information available in the three data sets, alternative definitions to the ones used to derive the empirical results presented in the paper are possible.

In the NMES, I have information on the date of retirement for those who report ever having retired-a self-reported definition of retirement. In addition, I also know whether an individual is currently working-if so, I know how many hours; if not, I know whether the stated reason for not working is retirement. This makes it possible to consider alternative (stricter) definitions of retirement, such as reported having retired and not currently working. In the estimation, implementing this stricter definition amounts to truncating individuals who are currently working even if they report a retirement date. Table 5 uses having ever retired and not currently working as the definition of retirement in the NMES.

The SIPP-CJR sample is confined to those who are receiving pension income, and the primary definition of retirement is the date at which an individual left the job from which he is receiving pension benefits. I can also further restrict the sample to those not currently in the labor force or who work fewer than a specified number of hours a week. To be consistent with the definition used in the NMES, retirement in table 7 is defined as having retired from a job and not currently working.

In the SIPP-EWH sample, which comprises individuals who did not work at all in the previous quarter, retirement corresponds to the date last worked. Some of these individuals, however, may be not working for reasons other than retirement, so I can also consider an alternative definition of retirement, which is not working and not in the labor force. This topical module included a question about the reason for leaving the last job, so the sample can be further confined to those individuals who report retirement as the reason for having left. Table 6 uses not working and being out of the labor force as the definition of retirement.

Table A2 compares the regression coefficients on retiree health insur- 
Table A2. Explaining Retiree Health Insurance Using Alternative Definitions of Retirement ${ }^{\mathrm{a}}$

\begin{tabular}{cc}
\hline Definition of retirement & $\begin{array}{c}\text { Retiree health } \\
\text { insurance coefficient }\end{array}$ \\
\hline National Medical Expenditure Survey & \\
Ever retired & -1.388 \\
Ever retired and not & $(0.208)$ \\
working & -1.400 \\
Ever retired, not working & $(0.217)$ \\
because retired & -1.462 \\
& $(0.227)$ \\
Survey of Income and Program & \\
Participation (EWH) & \\
Not working & -0.650 \\
& $(0.275)$ \\
Not working and & -0.627 \\
not in labor force & $(0.275)$ \\
Not working because retired & -0.899 \\
& $(0.283)$ \\
Survey of Income and Program & \\
Participation (CJR) & \\
Ever retired & -0.669 \\
Ever retired and not working & $(0.177)$ \\
Ever retired and working fewer & -0.723 \\
than 20 hours a week & $(0.193)$ \\
\hline
\end{tabular}

Source: Author's regressions based on data from the 1987 NMES and two supplements to the SIPP.

a. The table presents coefficients from a truncated regression model in which the dependent variable is the age at retirement. The sample consists of men aged 55-84. All specifications include education, race, and a complete set of cohort dummies. Standard errors are in parentheses.

ance using three different definitions of retirement for each of the three data sets. (These coefficients are derived from a truncated regression using the full sample of individuals aged 55-84.) As can be seen, the coefficients do not change significantly in any of the data sets in response to a different definition of retirement.

\section{Definition of Retiree Health Insurance}

In the NMES, retiree health insurance is defined from a question asked of all individuals over age 55 who reported ever having retired: 
whether they received retiree health insurance from the job from which they had retired. In both of the SIPP data sets, coverage by retiree health insurance is derived from a series of questions about whether an individual is covered by any private health insurance, whether this policy is held in the individual's own name, and whether it comes from a current or former employer. For individuals who are retired, it is likely that any employer-provided health insurance actually held by that individual is retiree health insurance, and this is therefore how retiree health insurance is defined. The NMES also includes a similar series of questions, which makes it possible to compare the definition of retiree health insurance used in the NMES with that used in the SIPP. The matrix below shows the percent of individuals reporting both types of coverage in the NMES.

$\begin{array}{cc}\text { With } & \text { Without } \\ \text { employer- } & \text { employer- } \\ \text { provided } & \text { provided } \\ \text { insurance } & \text { insurance }\end{array}$

With insurance

Without insurance

As one might expect, there are some discrepancies in the two definitions; however, the vast majority of individuals give consistent responses to both sets of questions. The empirical results in the NMES are not sensitive to the definition of retiree health insurance that is chosen. 


\section{Comments and Discussion}

Gary Burtless: The central issue treated in this paper is the effect of retiree health benefits on the labor force participation of older men. Does the availability of employer-sponsored retirement health insurance reduce the probability that older men will remain in the labor force?

I know little about the economics of health insurance, but I have given some thought to the issue of retirement. Some historical background might be helpful. The labor force participation rate of older men has been declining for much of the past century. According to others' estimates and my own tabulations from the Current Population Survey, the participation rate of men aged 60 and older fell from 67 percent in 1910 to 55 percent in $1940 .{ }^{1}$ It then fell to 40 percent in 1970 and to 28 percent in 1989.

The fall in male participation rates came to a halt in the middle of the 1980 s, but then it resumed in the past recession. I would guess, however, that the trend toward earlier retirement slowed very noticeably around 1983 or 1984. Several specialists on male labor supply-including Richard Burkhauser, Robert Moffitt, and myself-have suggested that the trend toward earlier retirement may even reverse over the medium term.

Many people believe the drop in participation rates can be explained by such factors as generous social security benefits, liberal private pensions, the introduction of Medicare, or employer-provided retirement health insurance. Some or all of these factors certainly played a role.

It seems doubtful that these factors can provide a complete explanation for the drop in participation rates. Labor force participation had already fallen by a significant amount before any of these developments became important. For example, participation among older men fell 12 percentage points in the three decades after 1910, even though the first

1. Ransom, Sutch, and Williamson (1991, p. 29). 
social security check was not mailed out until 1940. Another explanation for the fall in participation rates might be that the taste for leisure in old age has grown. Alternatively, rising lifetime wages and increased wealth may provide older Americans with the resources to indulge their unchanged tastes for retirement.

Brigitte Madrian wants to know how large a role retiree health insurance has played in the trend toward earlier retirement. More intriguingly, she asks whether health insurance reform could have a sizable or even a predictable effect on future male participation rates. I should say right off that I am a fan of this kind of exercise, and I think Madrian has done a very good job in carrying it out.

My comments will be divided into two parts. First, I consider Madrian's empirical estimates in comparison with those that would be obtained from an ideal data set. This is not meant as a criticism of her work, but as a guide to thinking about the reliability of the estimates of the coefficient she is attempting to measure. In the second part of my comments, I consider whether this coefficient, even if it is reliably estimated, can be used for practical policy analysis. Has Madrian estimated the number one needs to know to predict the consequences of health insurance reform on labor force participation?

\section{Empirical Estimation}

Madrian's paper surveys some past evidence on the subject of employer-provided health insurance and develops a great deal of new evidence. Though she is respectful of the earlier literature, she points out its serious shortcomings.

The main shortcoming-one that afflicts her own analysis as wellis the weakness of the data available to researchers. I was impressed in reading her literature survey by the ingenuity of earlier researchers in overcoming this limitation. It is equally impressive that Madrian has been able to find not one, not two, but three new data sets with which to analyze the issue. But these new data sets, like the earlier ones, suffer from serious deficiencies.

Madrian suggests that an ideal data set would contain longitudinal information on men who had not retired at the time of the initial survey but who had nearly all retired (or died) by the final survey. Each survey 
would elicit information on the availability and quality of employersponsored health insurance, before and after a worker's hypothetical retirement. In addition, the surveys would ask questions about other possible determinants of retirement—pension accruals, social security entitlement, health status, and wages, as well as similar information on the worker's spouse.

I think we can improve on this wish list. Let's be ambitious, and dream the impossible dream. An ideal data set would not only include the information Madrian mentions but would be collected from a group of workers who have been assigned to a retirement health plan (or to no plan at all) by the flip of a coin. In other words, the information would be derived from a classical experiment in which the randomly assigned treatment is the retirement health plan available to each worker. Because plan assignment is random, it would be uncorrelated with the worker's wage, health status, private pension plan, and social security entitlement.

Before dismissing this dream data set out of hand, remember that in the late 1970s and early 1980s the Rand Health Insurance Study actually managed to assign insurance plans on a random basis to a few thousand working families. Ethical considerations prevented Rand from assigning families to no health plan at all, so the data have little value for answering Madrian's question. But we could still use the Rolls-Royce standard of classical experiments as a benchmark for considering the data sets Madrian is actually forced to use.

The ideal data set would be longitudinal, and it would cover the labor market experience of a cohort from the time its retirement planning begins-say, age 50 or 55-until an age when most retirements have occurred-say, age 68 or 70 . This would ensure good contemporaneous information on each worker's labor force or retirement status and the factors affecting labor force decisions around the age of retirement.

Instead, Madrian is forced to rely on what are essentially crosssectional surveys of retirees, some of whom have retired 10 or 15 years before the date of the interview. She must depend on respondents' uncertain memories to reconstruct the timing of retirement. Even worse, she must infer the health insurance constraints facing a worker at the time of his retirement on the basis of his actual insurance coverage at the time of the interview. Needless to say, a number of things may have changed between the date the worker retired and the date of his inter- 
view. One thing that may have changed is the health insurance arrangements of the retired worker.

The perfect data set would contain information about social security and pension accruals covering the period before retirement occurs. The data sets used here contain information on retirees' actual social security or pension payment at the time of the interview. If the respondent is under age 62, I presume his social security entitlement is unknown-no actual payment is observed. If he is over age 62 , his private pension under a defined benefit plan that is coordinated with social security (such as the United Auto Workers' plan for Big Three auto workers) may be considerably lower than the pension he received right after retirement, assuming he retired before age 62 . Under the auto workers' pension plan, for example, the monthly pension falls when retirees reach age 62 and can begin to claim social security benefits.

A good data set would include information about respondents' health around the time of retirement-ideally, at least a year or two before it occurs. Every reliable retirement study known to me shows that health status is one of the most, if not the most, important determinants of retirement. All of Madrian's data sets have good information about respondents' health status-at the time of the interview. By definition, this interview occurred some time after retirement. Sensibly, Madrian does not use the health status data in her analysis.

The ideal data set would include information about respondents' hourly wage or potential annual earnings around the time he is considering whether to retire. The whole edifice of economic theory explaining when workers retire rests on the assumption that rational agents carefully weigh the attractiveness of retirement leisure against the price that must be paid in forgone earnings. Madrian lacks reliable information about wages or potential earnings.

Finally, the ideal data set would contain information about men who had been assigned to their retirement health plan on the basis of a random draw. Madrian does not have this kind of data. Instead, she is forced to use naturally occuring information. In the real world, workers are much more likely to be covered by retirement health insurance if they are also covered by a retirement pension plan; they are much less likely to be offered retiree health benefits if they lack pension coverage. It is clear from table 9 that men in the most generous pension plans were much more likely to be offered retiree health insurance than were 
men in less generous plans. The strong correlation between the generosity of employee pensions and the availability of retirement health plans-and the absence of reliable information about the characteristics of pension plans-makes it difficult to distinguish statistically between the separate contribution of retiree health plans and generous pension plans. By definition, a controlled random experiment would eliminate the correlation between retiree health plans and other features of the compensation package, such as the pension plan, that also affect the timing of retirement.

Random assignment of retirement health plans also gets around a more troublesome-and more subtle-statistical problem. It is likely that workers select their employers, to some extent, based on the generosity of different components of the compensation package. Workers who prefer to retire in their 50s should seek out employers who offer pension and health plans that make early retirement affordable and feasible. People who do not mind working into their late 60 s should accept jobs that, other things equal, offer less deferred compensation and more current money wages.

Madrian seems to suggest that this is a fairly minor consideration because most workers retire from jobs they took 20 or 30 years earlier, when retirement considerations were low on their list of priorities. I do not entirely agree. I live near Washington, D.C., so many of my friends and neighbors are civil servants. Many of them speak with fondness of attaining their 55th birthdays, when they will be free to retire. They also speak with great authority about the exact pension and health benefits that will be forthcoming when they reach age 55 .

Many workers are crudely aware of whether particular employers offer some kind of retirement benefit package. This is not exactly rocket science. Even 30-year-old workers realize that public employers, auto companies, and large paternalistic firms are excellent places to find jobs if one wishes to stop working before one is too old to enjoy the winter in Orlando or Sun City. If just 10 workers out of every 100 act on this knowledge, we could observe a large and statistically significant gap between the average retirement age of workers in companies with generous retirement plans and those who work for companies with less generous provision of retirement benefits.

If workers were randomly assigned to their retiree health plans when they were, say, 50 years old, the problem of employee self-selection 
would be avoided. Madrian cannot avoid the problem with the data sets she uses here. Any systematic difference between the preferences of workers in different kinds of companies would show up in her estimates as an "effect" of retiree health plans on early retirement.

Let me repeat that none of these remarks represents a criticism of the analysis Madrian has performed here. She has been dealt a bad hand, and she has played it extremely well. But the shortcomings of her data should make readers wary in interpreting the coefficients she has obtained. My view is that, along with the earlier findings described in her survey, her new estimates suggest that retirement health plans probably encourage workers to retire somewhat earlier than they would if offered a compensation package that lacked retirement health benefits. On the other hand, I would be surprised if a classical experiment of the type described would show that the effect of retirement health plans is to reduce male retirement ages by as much as a year, which is the estimate that Madrian seems to prefer.

This skepticism is based on my best guesses about the size and direction of the biases that affect the empirical estimates. For example, I can easily believe that employee self-selection might account for half the retirement difference between workers covered by retirement health plans and workers who are not covered.

In addition, my reading of the retirement literature is a bit different from Madrian's. Contrary to her interpretation that there is a wide range of estimates of the effect of social security on retirement, my reading is that the range of credible estimates is quite narrow. All of the reliable studies of this question - and there are many of them-find statistically significant but quantitatively small effects of social security benefit increases on retirement. The two studies she mentions-one by Hausman and Wise and the other by me-find very similar responses to the 196973 benefit liberalization, even though we used very different methods to analyze the episode. ${ }^{2}$ If this major liberalization in benefits had an effect as small as analysts believe, how likely is it that employer-sponsored retirement health insurance could have an effect as large as the one that Madrian finds? To find out, she might translate the social security benefit increase into a change in lifetime wealth and then calculate the change in lifetime wealth associated with most retiree health plans. Assuming the effect of a change in lifetime wealth on retirement is the same,

2. Hausman and Wise (1985) and Burtless (1986). 
whether caused by a social security benefit increase or by a retirement health plan, can she use estimates from the social security and retirement literature to make a guesstimate of the impact of retirement health plans on retirement? I suspect the implied effect would be smaller than the one Madrian reports in this paper.

\section{Policy Applications}

Even assuming that Madrian has obtained a robust estimator of the effect of retirement health plans on age at retirement, can one use her estimate to predict the consequences of health insurance reform? Remember that the coefficient that would be produced by the ideal experiment would measure the effect on a representative sample of men of the effect of providing (or withholding) retirement health insurance as a component of employee compensation.

I see a couple of problems with the policy analysis that is attempted in this paper. The financing and personnel policy implications of a change in retiree health benefits make the population work response very uncertain. If retiree health insurance is added to employee compensation, how do employers pay for it? What other components of the compensation package might change? There is an implicit assumptionnot in this paper but in much of the policy discussion-that employees are offered a free lunch: retirement health benefits are added to the compensation package; nothing else about the package changes.

This cannot be right. If employers have offered retirement health benefits as a way to attract or retain a certain class of highly desired workers, health insurance reform will leave them with the problem of attracting or retaining these same kinds of employees when all other employers offer similar or identical retiree health benefits. Perhaps it would be sensible to modify some other component of the compensation package-say, employee pension accruals-to accomplish the same recruitment and retention goals that were formerly accomplished by the firm's retirement health plan? If this is true, then health insurance reform will not have the pure supply-side effect predicted in table 11. There will be a demand-side response of employers: Some will change other elements of their compensation package to achieve the goals formerly achieved by their retiree health insurance.

Of course, most employers do not offer retiree health benefits. Many do not even offer worker health benefits. Health insurance reform may 
involve requiring all employers to offer and partially to finance health benefits, at least for their current workers. Reform may also involve guaranteed access to subsidized insurance for retired workers under age 65. Depending on the plan that is finally adopted, reform will involve cross-subsidies from some kinds of employers to others and from some classes of workers to others. The cross-subsidies in President Clinton's current plan flow mainly from young workers to the old and from general taxpayers to employers that now offer generous retiree health benefits.

The increased subsidies that will be received by older workers will, on the one hand, make early retirement more feasible for these workers. The new subsidies will reduce the consumption losses workers currently suffer as a result of retirement: workers will retain access to subsidized health insurance even after they leave their career jobs.

On the other hand, for most employers, the subsidies will reduce the cost of employing older workers. Workers who are age 50 and older will be cheaper, hence more attractive to hire. Firms may adjust by offering higher wages or liberalizing other fringe benefits in order to retain their older workers. They may reduce discrimination against older job applicants in their hiring. From the point of view of older workers, these changes will raise the attractions of remaining on the payroll or reduce the impediments to becoming reemployed after a layoff.

A small-scale classical experiment, like the one I described earlier, would not cause employers to modify their compensation package. As a result, the experiment would put analysts in a position to observe the pure supply-side response of workers to the availability of retiree health benefits. But analysts would not be in a position to observe the full consequences of the benefits, because the reaction of employers would be missed.

The cross-subsidies proposed by President Clinton will raise the lifetime wealth of older workers. On balance, I expect that that rise in wealth would reduce their retirement age. But part of the increase in lifetime wealth may take the form of higher wages or compensation, which would tend to keep older workers on their jobs longer. This partly offsets the effects of greater lifetime wealth. It is hard to believe that Madrian's simulation estimates, shown in table 11, capture the full response of older workers to health insurance reform, once we take account of the probable response of employers. 
Jonathan Gruber: As health care reform careens forward, the cry of "jobs, jobs, jobs" is once again in the air. Much of the opposition to employer mandates is based on the contention that this net new cost to employers will lead to reductions in labor demand and subsequent layoffs. Yet, most analyses of the labor market effects of health care reform project fairly small job losses, even potential job gains. ${ }^{1}$ In fact, there is a much more important supply-side labor market effect that has not featured prominently in this debate: the role of health insurance-induced immobilities, or "job lock." While this was an important motivation for reform, there has been little rigorous analysis of the phenomenon. Given the potential relative magnitude of the demand- and supplyside effects of reform, this represents a key misallocation of research resources. Brigitte Madrian's paper is an important first step toward remedying this misallocation.

"Job lock" comes in at least four varieties: reduced mobility across jobs, reduced mobility off of the welfare rolls and into the labor force, reduced mobility of prime-age workers from jobs to out of the labor force, and reduced mobility from work to retirement. Recent analysis, some of it by Madrian herself, has focused on the first two of these phenomena. She turns her attention in this paper to the last, which might be labeled "retirement lock." It is interesting to note that little attention has been paid to the third of these effects, which may arise from health insurance "locking" secondary earners into their jobs when they would prefer to be at home. The "voluntary" reduction in the prime-age labor force, resulting from loosening this form of job lock, could be much larger than the "involuntary" reduction from an employer mandate.

Nevertheless, there are a number of reasons to believe that the retirement effect is the largest of these distortions, as Madrian is careful to note in her paper. Not only is the average level of medical costs much higher for the potential male retiree than for the younger worker, but the variance is much higher as well; one standard deviation of medical expenditures for people aged 55-64 represents approximately 30 percent of their average income. Thus, for a worker with insurance on the job but without retiree coverage, early retirement could be associated with

1. Employee Benefit Research Institute (1994). 
both a decrease in the level and a substantial increase in the variance of consumption. A large body of literature has documented that health status is an important determinant of retirement, yet, until recently, there was no study of the effect of health insurance. Madrian's is the most comprehensive of the recent wave of studies to do so. ${ }^{2}$

The methodology employed here is to examine a sample of retired individuals and to use information on their age at retirement, as well as their current coverage by retiree health insurance, to model the effect of such coverage on retirement ages. Madrian finds fairly sizable and significant effects of retiree insurance in three different data sets: coverage is associated with a reduction in the retirement age of 5 to 16 months. This is an impressive undertaking, which is careful in its analysis and broad in its scope. The author deserves special notice for being brave enough to take her analysis to three distinct data sets. And she is rigorous throughout the body of the text and the appendix in exploring the sensitivity of her findings to variations in the specification.

An important statistical issue, which the author readily acknowledges in the text, arises from the fact that the sample is selected based on having retired. This potentially biases the results downward, since individuals will not be in the sample if they have not yet retired because of a lack of retiree coverage, understating the disincentive effects of not having coverage. The author deals with this problem in two sensible ways: by using a truncated normal estimator and by simply cutting off the age distribution below age 65 or 70 , by which time most of the sample has retired. Unfortunately, these approaches often yield quite different estimated effects.

Each approach has a shortcoming, but I lean toward the cutting off the distribution. The truncated normal estimator, under certain assumptions, does account for this selection problem. But, by including those who are younger than age 65, Madrian still does not account for an important feature of the retiree insurance landscape: the availability of continuation coverage. In a number of states before October 1986, and in all states afterward, workers who left their jobs could continue to buy group insurance from their employers, at the average group rate, for up to 18 months after leaving. This provides a substantial subsidy to early retirees, as continuation coverage is generally much cheaper than age-

2. The others being Gruber and Madrian (1993a, 1993b); Gustman and Steinmeier (1992); Karoly and Rogowski (1993); and Lumsdaine, Stock, and Wise (forthcoming). 
rated individual insurance, and as a result approximately two-thirds of eligible retirees take up such coverage. ${ }^{3}$ Unfortunately, Madrian is unable to infer whether the insurance coverage that she observes is from continuation benefits or retiree health insurance. ${ }^{4}$ If these two different types of coverage have differential effects on retirement, then it is important to separate them. But this is difficult to do in the under-65 sample.

Truncation of the sample at age 65 controls for continuation benefits, since such coverage is not available to those on Medicare. However, this introduces a different bias, arising from the different mortality prospects of those still alive after age 65. If, among the set of early retirees, those with retiree health insurance were likely to live longer, then the post-65 sample will overstate the influence of retiree coverage. The author notes that this could arise if retiree health insurance improves the health of early retirees, but she claims that the resulting bias is likely to be small; this contention is supported by the lack of convincing evidence that health insurance coverage actually matters for adult health. ${ }^{5}$

However, even if insurance does not matter for health, the bias will still be present if those who select to work in firms that offer retiree coverage are healthier than those who do not. For example, if sicker individuals work at firms with retiree coverage, retire early, and die before age 65 , then there will be a bias against her findings. Madrian cannot examine health differences between those who do and do not have coverage, since among those already retired the coverage itself may be affecting health. But it may be instructive for future analysis to examine the health of workers at firms that do and do not offer retiree coverage. If it does not significantly differ, then I would prefer the second method of controlling for selection.

There are three major issues that I would like to raise regarding the basic findings. First, this paper has clearly established a strong correlation between retiree coverage and retirement ages; this is documented most strikingly in figure 1 . But is this relationship causal? There are at least two alternative explanations. The first, and probably less important, is selection by workers with a propensity to retire early into

3. Gruber and Madrian (1993a).

4. She has an explicit question about retiree coverage in only one of her three data sets, and even for that question the respondents may have confused retiree and continuation coverage.

5. Manning and others (1987). 
firms that offer retiree health insurance. The author addresses this potential problem by noting that most of the workers who retire have very long tenures and therefore are not likely to select a firm based on retiree coverage. But even if the average retiring worker has a long tenure, so long as the marginal retiring worker is selecting the firm it will lead to a bias of the type described above. This is especially true if there are peer effects in retirement, whereby one (short-tenure) worker's retirement decision affects the decision of other (long-tenure) workers in the same workplace.

One way to assess the importance of this selection problem follows the long-standing presumption in many empirical articles that "unobservables go the same way as observables." This philosophy suggests that the author's contention that selection is unimportant could be buttressed by examining the distribution of characteristics at firms that do and do not offer coverage. That is, if one were to predict the propensity to retire based on observable characteristics aside from retiree coverage, would that predicted value be higher in firms with retiree coverage? If so, worker selection may be important.

The more important potential problem for the analysis is the fact that other omitted characteristics of firms may be correlated with the provision of retiree coverage. The most obvious of these potential omitted variables is pension generosity. The author addresses this point as well as possible given the data limitations, running the regressions with industry and occupation controls, as well as only among those with pensions. But the fact, admirably highlighted by the paper, that the average pension benefit of workers who have retiree insurance is higher than that of workers without such insurance does suggest further differences in pension generosity.

There are two means at the author's disposal for addressing this concern. One is to do the opposite of what she has done already: run the regressions for those without any pension income in her SIPP-EWH sample. There is no issue of omitted pension generosity in this specification. Eyeballing the results in table 6, it appears that this would support her causal inferences, since the results for the full sample are about the same as those for the sample with pension income. Alternatively, she could control for pension generosity, which is available in the SIPPCJR data set. Of course, pension benefits may differ with age in a way that does not proxy generosity but simply differential inflation and ad- 
justment over the retirement period. This could be addressed by first correcting pension benefits for age in an auxiliary regression and including the corrected value in the base regression. While these data are not ideal, since it is pension "spikes" and not benefit levels that are found to be most important in determining retirement, this control could move us part of the way toward resolving this difficult issue.

It is difficult to gauge the importance of these ommitted variables. But one further means of assessing Madrian's results is to compare them to previous research. She finds that having retiree health insurance raises the probability of early retirement by approximately 7.5 percentage points in the SIPP-EWH sample. On average, for this sample, the probability that an individual retired early was 50.6 percent, so that her findings imply an increase in the early retirement probability of 14.8 percent. In related papers, the author and I have examined the effect on retirement of the much more limited coverage made available by continuation mandates. ${ }^{6}$ This coverage was assigned exogenously to individuals by state legislatures, overcoming these potential omitted variable biases. We found that one year of continuation coverage raised the probability of early retirement by 5.4 percent, an effect that is roughly one-third as large. However, the average early retiree in the SIPP-EWH sample is retired for 3.1 years, so that on an annual basis Madrian's estimates are almost exactly the same as those uncovered in our earlier work. This suggests that there is little upward bias to the findings in this paper.

The second issue raised by the paper is whether these findings can explain the "excess" retirement at age 65. A number of authors, most recently Lumsdaine, Stock, and Wise, have noted that, even controlling for the structure of pension and social security incentives, individuals are excessively likely to leave their job at age $65 .{ }^{7}$ A natural explanation this phenomenon is the presence of Medicare, which provides highly subsidized insurance coverage to those over 65 . In this paper, however, Madrian finds that this age 65 "spike" is present for those with retiree insurance coverage also. This would seem to refute the role of Medicare as a causal mechanism.

This test could be refined along two dimensions. First, there has been no study that has considered the interaction between retiree insurance coverage and pension incentives around age 65 . If those firms that pro-

6. Gruber and Madrian (1993a, 1993b).

7. Lumsdaine, Stock, and Wise (1993). 
vide retiree coverage also provide generous pension "spikes" at age 65 , this could explain why the pattern of excess retirement persists even among this subsample. Second, one explanation for the limited estimated role of Medicare is that the coverage is not very generous, with large copayments and high out-of-pocket maximums. This can be tested by splitting the effect of retiree coverage on retirement into the effect on the pre- 65 retirement decision and the post-65 retirement decision. If it is the limited nature of Medicare that reduces its effects, then "topping off" Medicare with retiree coverage should still have effects on post-65 retirement decisions. This test obviously cannot be undertaken with Madrian's data, since it would involve selecting on the dependent variable, age at retirement. But it can be undertaken with data from the Health and Retirement Survey, a forthcoming longitudinal survey of older workers, which will allow hazard modeling of the retirement decision.

Finally, we come to the most timely of the issues: what do these results imply for health care reform? For those without retiree coverage, the availability of lower-cost group insurance on the job but expensive individual insurance after retirement is a potential source of inefficiency. The fact that workers respond so strongly to retiree coverage suggests that there may be large welfare gains from reducing this inefficiency by increasing the availability of group coverage for early retirees. That is, a policy of continuation coverage that is not limited to 18 months but extended until age 65 would increase welfare by "leveling the playing field" between work (where presumably the cost of insurance is paid through lower wages) and retirement (where it would be paid out of pocket). Distortions between work and nonwork could be further mitigated by making health insurance premiums paid on the worker's behalf taxable. This would have the additional advantage that it would help compensate for the reduced income and payroll tax collections that would occur if retirement increased.

Under the Clinton plan, group coverage is made available to retirees through purchase from regional alliances, which is mandatory for all individuals and all but the largest firms. However, an important additional feature of the Clinton plan is that the government pays the majority of the cost of insurance for those over 55 who label themselves (arbitrarily) "early retirees," while those under that age have to pay their own insurance costs (subject to a subsidy schedule). Thus, rather than leveling the 
playing field, the Clinton plan has tilted it toward retirement. This plan involves a large intergenerational redistribution, as younger workers both pay higher (community-rated) premiums to support older workers in their regional pool and pay higher taxes to support the subsidies going to "early retirees." To the extent that the plan is in place for many years, there is no redistribution from a lifetime perspective. However, given the likely constant evolution of health policy in the coming decades, this could be an important short-run horizontal inequity.

The efficiency cost of such a redistribution is threefold. First is the distortion to the labor supply of young workers from financing this subsidy. Second is the distortion to the retirement decision from having the subsidy. Third is the distortion to the choice of partial versus full retirement. Completing the missing group insurance market for older workers would allow them to optimize over their hours worked, perhaps partially retiring from a full-time job with benefits to a part-time job without benefits. But restricting the subsidy to only full retirees distorts this decision margin as well, leading to excessive full retirement. Madrian finds that the effect of retiree coverage in her data are fairly insensitive to the definition of retirement chosen. However, employer policies may be more flexible with respect to partial and full retirement than would be the Clinton subsidy. Evidence on the treatment of full and partial retirement by employer retirement plans would be helpful in addressing this point.

To summarize, I think that this is a very well executed paper on an important topic. The author has both been careful to consider detailed modeling issues and honest about possible pitfalls in her strategy. I think that further analysis of this question with the forthcoming Health and Retirement Survey will help to pin down some of the remaining questions. But the author has convinced me that the basic results uncovered here will bear out under further scrutiny with improved data.

\section{General Discussion}

Much of the discussion concerned how data limitations complicate the interpretation of the results. Bruce Petersen suggested that the omission of retiree wealth could lead to biased parameter estimates. Wealth 
is likely to be correlated with postretirement health benefits, because higher-wage jobs are more likely to offer these benefits. Since greater wealth itself may encourage earlier retirement, the results may overstate the effect of health benefits. Madrian suggested that pensions are the most important omitted factor. She added, however, that data on the level of pensions alone would be of limited value in separating the effects of postretirement health benefits from the effects of pensions. Recent research suggests that differences in the timing of eligibility for pensions are more important for retirement decisions than the level of pensions, so that data on the timing of eligibility for pensions would be required.

John Shoven noted that firms frequently offer "window" plans in which benefits are temporarily sweetened for those who retire within a certain time period, and he suggested this could affect the results in the paper. Based on preliminary results from other research she has done, Madrian reported that when "window" plans are offered, the health care component typically is not sweetened. Retirement associated with window plans does not appear to be related to improvements in postretirement health benefits. Although window plans may be offered more frequently by firms that have good retiree health benefits, Madrian doubted that the presence of window plans affected the results in the paper.

Robert Moffitt suggested that observations on individuals who are still working might be needed to avoid selection bias that may remain even in the truncated regressions of the paper. With such additional data, retirement probabilities for people of the same age could be examined directly to see whether they are increased by the presence of retirement health insurance benefits. Data on working individuals could also address the possibility that there are systematic differences between workers in firms that do and do not offer retiree health benefits.

James Tobin noted that many retirees remain in the labor force in one way or another. Thus, knowing how increasing the availability of retirement health benefits would affect the number of retirees does not adequately describe how it would affect the supply of labor hours. In addition to knowing how many individuals would be induced to retire by improvements in retiree health benefits, it would be useful to examine the changes in hours worked by such individuals.

Madrian commented on Gary Burtless's suggestion that estimates of the effect of social security on retirement decisions could be used to check the plausibility of her results. This could be done by assuming that 
the present value of postretirement health benefits received by an individual would affect retirement in the same way as additions to lifetime wealth received in the form of social security. Madrian observed that this calculation would be complicated, because the increment to wealth from retiree health benefits depends upon how soon before eligibility for Medicare an individual retires and because their value depends importantly on preexisting medical conditions of individuals. She noted, however, that such wealth effects could be substantial; the present discounted value of postretirement health insurance may far exceed that of social security benefits for a worker retiring at age 55 from General Motors.

Turning to the effects on labor demand, William Brainard suggested that requiring firms to help pay for postretirement insurance might lower the demand for labor and reduce other forms of compensation. Estimating the effects on employment of improved retiree health plans requires knowledge of this response. Burtless suggested that these responses might completely offset the effect of improved retirement health benefits; if firms were meeting their goals for recruitment and retention before such benefits, they would look for other changes to offset the effects of the improved benefits on early retirement. Finally, Greg Mankiw asked whether we should regard it as good or bad if retiree health benefits induce earlier retirement. He noted that every developed country has a social security system designed to encourage early retirement, raising the possibility that early retirement is actually a policy goal. 


\section{References}

A. Foster Higgins \& Co., Inc. 1990. Health Care Benefits Survey 1990, Report 4: Retiree Health Care. Princeton, N.J.: A. Foster Higgins \& Co., Inc.

$\rightarrow$ Bazzoli, Gloria J. 1985. "The Early Retirement Decision: New Empirical Evidence on the Influence of Health.' Journal of Human Resources 20(2): 214 34.

$\rightarrow$ Brown, James N., and Audrey Light. 1992. "Interpreting Panel Data on Job Tenure." Journal of Labor Economics 10(3): 219-57.

Buchmueller, Thomas C., and Robert G. Valletta. 1994. "Employer-Provided Health Insurance and Worker Mobility: 'Job-Lock' or Not?' Unpublished paper. University of California, Irvine (February).

$\rightarrow$ Burtless, Gary. 1986. "Social Security, Unanticipated Benefit Increases, and the Timing of Retirement.' Review of Economic Studies 53(5): 781-805.

- 1987. "Occupational Effects of the Work and Health Capacity of Older Men.' In Work, Health, and Income Among the Elderly, edited by Gary Burtless. Washington: Brookings.

Chollet, Deborah J. 1989. "Retiree Health Insurance Benefits: Trends and Issues.' In Retiree Health Benefits: What Is the Promise? Washington: Employee Benefit Research Institute.

Congressional Research Service. 1989. Costs and Effects of Extending Health Insurance Coverage. Washington: U.S. Government Printing Office.

Cooper, Philip F., and Alan C. Monheit. 1993. "Does Employment-Related Health Insurance Inhibit Job Mobility?' Inquiry 30: 400-16.

de Lissovoy, Gregory, and others. 1990. "Changes in Retiree Health Benefits: Results of a National Survey." Inquiry 27: 289-93.

Ellwood, David T., and Kathleen Adams. 1990. "Medicaid Mysteries: Transitional Benefits, Medicaid Coverage, and Welfare Exits.' Health Care Financing Review, 1990 Annual Supplement: 119-31.

Employee Benefit Research Institute. 1990. Employee Benefit Notes. Washington: Employee Benefit Research Institute (November).

1993. Public Attitudes on Benefit Trade Offs. Washington: Employee Benefit Research Institute.

- 1994. Health Reform: Examining the Alternatives. Washington: Employee Benefit Research Institute.

Faber, Joseph F. 1982. Life Tables for the United States, 1900-2050. Washington: U.S. Department of Health and Human Services, Social Security Administration.

Farley, Pamela J. 1986. Private Health Insurance in the United States. Rockville, Md.: U.S. Department of Health and Human Services, Public Health Service, National Center for Health Services Research and Health Care Technology Assessment.

$\rightarrow$ Gruber, Jonathan. 1994. "The Efficiency of a Group-Specific Mandated Benefit: Evidence from Health Insurance Benefits for Maternity." American Economic Review (forthcoming). 
and Alan Krueger. 1990. "The Incidence of Mandated Employer-Provided Insurance: Lessons from Workers' Compensation Insurance.' In Tax Policy and the Economy, Volume 5, edited by David Bradford. Cambridge, Mass.: MIT Press.

— Early Retirement." Working Paper 4469. Cambridge, Mass.: National Bureau of Economic Research (September).

ment: Evidence from the Availability of Continuation Coverage." Working Paper 4594. Cambridge, Mass.: National Bureau of Economic Research (December).

$\longrightarrow \rightarrow$, and Brigitte C. Madrian. 1994. "Limited Insurance Portability and Job Mobility: The Effects of Public Policy on Job-Lock.' Industrial and Labor Relations Review (forthcoming).

Gustman, Alan L., and Thomas L. Steinmeier. 1993. "Employer Provided Health Insurance and Retirement Behavior." Working Paper 4307. Cambridge, Mass.: National Bureau of Economic Research (March).

$\rightarrow$ Hausman, Jerry A., and David A. Wise. 1977. "Social Experimentation, Truncated Distributions, and Efficient Estimation.'" Econometrica 45(4): 919-38. 1985. "Social Security, Health Status, and Retirement."' In Pensions, Labor and Individual Choice, edited by David A. Wise. Chicago: University of Chicago Press.

Hewitt Associates. 1990. Survey of Retiree Medical Benefits. Lincolnshire, Ill.: Hewitt Associates.

Holtz-Eakin, Douglas. 1994. "Health Insurance Provision and Labor Market Efficiency in the United States and Germany." In Social Protection Versus Economic Flexibility: Is There a Tradeoff?, edited by Rebecca M. Blank. Chicago: University of Chicago Press.

- John R. Penrod, and Harvey S. Rosen. 1994. "Health Insurance and the Supply of Entrepreneurs.' Unpublished paper. Princeton University (March).

Jianakoplos, Nancy Ammon, Paul L. Menchick, and F. Owen Irvine. 1989. "Using Panel Data to Assess the Bias in Cross-Sectional Inferences of LifeCycle Changes in the Level and Composition of Household Wealth." In The Measurement of Saving, Investment and Wealth, edited by Robert E. Lipsey and Helen Stone Tice. Chicago: University of Chicago Press.

Karoly, Lynn A., and Jeannette A. Rogowski. 1993. "The Effect of Health Insurance on the Decision to Retire." Unpublished paper. RAND Corporation (May).

Lumsdaine, Robin L., James H. Stock, and David A. Wise. Forthcoming. "Pension Plan Provisions and Retirement: Men and Women, Medicare, and Models.' In Studies in the Economics of Aging, edited by David A. Wise. Chicago: University of Chicago Press.

Maddala, G. S. 1983. Limited-Dependent and Qualitative Variables in Econometrics. Cambridge: Cambridge University Press.

$\rightarrow$ Madrian, Brigitte C. 1994. "Employment-Based Health Insurance and Job- 
Mobility: Is There Evidence of Job-Lock?' Quarterly Journal of Economics 109(1): 27-54.

$\rightarrow$ Manning, Williard, and others. 1987. "Health Insurance and the Demand for Medical Care: Evidence from a Randomized Experiment.' American Economic Review 77(3): 251-77.

McClellan, Mark, and Jonathan Skinner. 1992. "The Distribution of Medicare Benefits Among the Elderly: Preliminary Results from Texas and New York.' Unpublished paper. Massachusetts Institute of Technology (October).

$\rightarrow$ Moffitt, Robert, and Barbara L. Wolfe. 1992. "The Effect of the Medicaid Program on Welfare Participation and Labor Supply.' Review of Economics and Statistics 74(4): 615-26.

Penrod, John R. 1993. "Health Care Costs, Health Insurance, and Job Mobility." Unpublished paper. Princeton University (November).

Piacentini, Joseph S., and Jill D. Foley. 1992. EBRI Databook on Employee Benefits. Washington: Employee Benefit Research Institute.

Quinn, Joseph F., Richard V. Burkhauser, and Daniel A. Myers. 1990. Passing the Torch: The Influence of Economic Incentives on Work and Retirement. Kalamazoo, Mich.: W. F. Upjohn Institute for Employment Research.

Ransom, Roger L., Richard Sutch, and Samuel H. Williamson. 1991. "Retirement: Past and Present." In Retirement and Public Policy, edited by Alicia H. Munnell. Dubuque, Iowa: Kendall/Hunt Publishing Co.

Sammartino, Frank J. 1987. "The Effect of Health on Retirement." Social Security Bulletin 50(2): 31-47.

Samwick, Andrew A. 1993a. "Retirement Incentives in the 1983 Pension Provider Survey." Unpublished paper, Massachusetts Institute of Technology (April).

- 1993b. "The Joint Effect of Social Security and Pensions on the Timing of Retirement: Some New Evidence." Unpublished paper. Massachusetts Institute of Technology (November).

Smith, George Davey, and Matthias Egger. 1992. "Socioeconomic Differences in Mortality in Britain and the United States." American Journal of Public Health 82(8): 1079-81.

U.S. Bureau of Labor Statistics. 1989. Employee Benefits in Medium and Large Firms, 1988. Washington: U.S. Department of Labor.

- 1991. Employee Benefits in Small Private Establishments, 1990. Washington: U.S. Department of Labor.

Wilkinson, Richard G. 1992. "National Mortality Rates: The Impact of Inequality?" American Journal of Public Health 82(8): 1082-84.

Yelowitz, Aaron S. 1993. "The Medicaid Notch, Labor Supply, and Welfare Participation: Evidence from Eligibility Expansions.' Unpublished paper. Massachusetts Institute of Technology (November). 